\title{
Land surface phenology from MODIS: Characterization of the Collection 5 global land cover dynamics product
}

\author{
Sangram Ganguly ${ }^{\mathrm{a}, *}$, Mark A. Friedl ${ }^{\mathrm{b}}$, Bin Tan ${ }^{\mathrm{c}}$, Xiaoyang Zhang ${ }^{\mathrm{d}}$, Manish Verma ${ }^{\mathrm{b}}$ \\ a Bay Area Environmental Research Institute/NASA Ames Research Center, MS 242-4, Moffett Field, CA 94035, USA \\ ${ }^{\mathrm{b}}$ Department of Geography \& Environment, Boston University, 675 Commonwealth Avenue, Boston, MA 02215, USA \\ ' Earth Resources Technology, Inc., NASA Goddard Space Flight Center, Code 614.5, Greenbelt, MD 20771, USA \\ d Earth Resources Technology, Inc., 10810 Guilford Road, Suite 105, Annapolis Junction, MD 20701, USA
}

\section{A R T I C L E I N F O}

\section{Article history:}

Received 29 September 2009

Received in revised form 8 April 2010

Accepted 10 April 2010

\section{Keywords:}

MODIS phenology

Land cover dynamics

Land cover

Vegetation dynamics

MODIS Collection 5

\begin{abstract}
A B S T R A C T
Information related to land surface phenology is important for a variety of applications. For example, phenology is widely used as a diagnostic of ecosystem response to global change. In addition, phenology influences seasonal scale fluxes of water, energy, and carbon between the land surface and atmosphere. Increasingly, the importance of phenology for studies of habitat and biodiversity is also being recognized. While many data sets related to plant phenology have been collected at specific sites or in networks focused on individual plants or plant species, remote sensing provides the only way to observe and monitor phenology over large scales and at regular intervals. The MODIS Global Land Cover Dynamics Product was developed to support investigations that require regional to global scale information related to spatiotemporal dynamics in land surface phenology. Here we describe the Collection 5 version of this product, which represents a substantial refinement relative to the Collection 4 product. This new version provides information related to land surface phenology at higher spatial resolution than Collection 4 (500-m vs. 1-km), and is based on 8-day instead of 16-day input data. The paper presents a brief overview of the algorithm, followed by an assessment of the product. To this end, we present (1) a comparison of results from Collection 5 versus Collection 4 for selected MODIS tiles that span a range of climate and ecological conditions, (2) a characterization of interannual variation in Collections 4 and 5 data for North America from 2001 to 2006, and (3) a comparison of Collection 5 results against ground observations for two forest sites in the northeastern United States. Results show that the Collection 5 product is qualitatively similar to Collection 4. However, Collection 5 has fewer missing values outside of regions with persistent cloud cover and atmospheric aerosols. Interannual variability in Collection 5 is consistent with expected ranges of variance suggesting that the algorithm is reliable and robust, except in the tropics where some systematic differences are observed. Finally, comparisons with ground data suggest that the algorithm is performing well, but that end of season metrics associated with vegetation senescence and dormancy have higher uncertainties than start of season metrics.
\end{abstract}

(ㄷ) 2010 Elsevier Inc. All rights reserved.

\section{Introduction}

Investigations focused on monitoring and modeling biospheric processes require accurate information related to spatio-temporal dynamics in ecosystem properties. Because vegetation phenology affects terrestrial carbon cycling across a wide range of ecosystem and climate regimes (Baldocchi et al., 2001; Churkina et al., 2005; Richarson et al., 2009), accurate information related to phenology is important to studies of regional-to-global carbon budgets. The presence of leaves also influences land surface albedo (Moore et al., 1996; Ollinger et al., 2008) and exerts strong control on surface

\footnotetext{
* Corresponding author.

E-mail address: sangramganguly@gmail.com (S. Ganguly).
}

radiation budgets and the partitioning of net radiation between latent and sensible heat fluxes (Chen \& Dudhia, 2001; Yang et al., 2001). Thus, the phenological dynamics of vegetated ecosystems influence a host of eco-physiological processes that affect hydrologic processes (Hogg et al., 2000), nutrient-cycling, (Cooke \& Weih, 2005), and landatmosphere interactions (Heimann et al., 1998).

In recent years, growing season dynamics including shifts in the timing of bud burst, leaf development, senescence, and changes in growing season length have been widely studied in the context of ecosystem responses to climate change (Cleland et al., 2007). Studies using AVHRR data have concluded that northern hemisphere temperate and boreal regions $\left(\sim 40^{\circ}-70^{\circ} \mathrm{N}\right)$ experienced increased growing season greenness related to surface warming during the period 1981 to 1999 (Myneni et al., 1997; Zhou et al., 2001). More recent studies utilizing a longer record of AVHRR data suggest a more 
complex pattern with evidence of "browning" trends in the boreal forests of Southern Alaska, Canada, and in the interior of Russia (Angert et al., 2005; Ganguly et al., 2008; Goetz et al., 2005; Zhang et al., 2007). Complex phenological responses have also been observed in controlled experiments where warming accelerated greening of plant canopies, but elevated $\mathrm{CO}_{2}$ and nitrogen fertilization delayed flowering (Cleland et al., 2007). These biophysical and biochemical processes both influence and are diagnostic of ecosystem-climate interactions. As a consequence, there is substantial need to accurately characterize the phenology of ecosystems, and by extension, the response of ecosystems to changes in climate (Morisette et al., 2009).

Moderate resolution satellite remote sensing provides global high temporal frequency measurements of land surface properties and is therefore well suited for monitoring seasonal-to-decadal patterns and trends in regional-to-global phenology (de Beurs \& Henebry, 2005; Reed et al., 1994; White et al., 1997; Zhang et al., 2003). Landsat MSS was the first space-borne sensor used to characterize the seasonality of vegetation at landscape and regional scales (Thompson \& Wehmanen, 1979). However, detecting phenological transition dates requires higher temporal resolution than is afforded by Landsat-class instruments, and coarse-to-moderate spatial resolution sensors such as the AVHRR (Goward et al., 1985), MODIS (Zhang et al., 2003) and SPOT-VEGETATION (Delbart et al., 2006) are more commonly used for this purpose. Indeed, the utility of such sensors for studies of land surface phenology has been established for over 20 years (Justice et al., 1985). Over the last two decades, a number of different approaches have been developed for this purpose. The most common of these methods include threshold-based techniques (Jonsson \& Eklundh, 2002; White et al., 1997), methods based on spectral analysis (Jakubauskas et al., 2001; Moody \& Johnson, 2001), and inflection point estimation in time series of vegetation indices (Moulin et al., 1997; Zhang et al., 2003). All methods use time series of vegetation indices to identify the timing of phenological transition dates such as the start and end of the growing season.

Since 2000, the Moderate Resolution Imaging Spectroradiometer (MODIS) has provided an excellent basis for regional-to-global scale studies of land surface phenology (Ahl et al., 2006; Fisher \& Mustard, 2007; Zhang et al., 2003, 2006). The objective of this paper is to present an overview and characterization of the new Collection 5 (C5) MODIS Global Land Cover Dynamics (MLCD) product, which is produced globally at a spatial resolution of 500-m and is available from 2001 to present. Below we describe refinements to the MLCD algorithm and present a characterization of the C5 product via (1) comparison with Collection 4 (C4) data, (2) assessment of variability in C5 results across multiple years, and (3) comparison of C4 and C5 data with field data.

\section{MODIS land cover dynamics algorithm and product}

\subsection{Product overview, input data, and pre-processing}

The MLCD algorithm, as presented in Zhang et al. (2003, 2006), is used for this work. This algorithm characterizes vegetation growth cycles using four transition dates estimated from time series of MODIS enhanced vegetation index (EVI) data: (1) greenup: the date of onset of EVI increase; (2) maturity: the date of onset of EVI maximum; (3) senescence: the date of onset of EVI decrease; and (4) dormancy: the date of onset of EVI minimum. These transition dates correspond to the first four science data sets (SDS) associated with the MLCD product (Table 1). Note that the SDS names use "greenness", not EVI. To be more precise, and because these transition dates are estimated from temporal dynamics in the EVI, here we specifically refer to transitions in EVI (onset of increase in EVI, etc.). In Section 3.4 we compare these dates with measurements of forest canopy phenology collected on the ground.
Table 1

Science data sets included in the MODIS Land Cover Dynamics Product (combined Terra and Aqua Product Identifier MCD12Q2).

\begin{tabular}{|c|c|c|c|c|}
\hline Science data set name & Units & $\begin{array}{l}\text { Data } \\
\text { format }\end{array}$ & Valid range & $\begin{array}{l}\text { Scale } \\
\text { factor }\end{array}$ \\
\hline $\begin{array}{l}\text { Onset_Greenness_Increase } \\
\text { Onset_Greenness_Maximum } \\
\text { Onset_Greenness_Decrease } \\
\text { Onset_Greenness_Minimum }\end{array}$ & $\begin{array}{l}\text { Day of } \\
\text { year }\end{array}$ & $\begin{array}{l}16 \text { bit } \\
\text { signed } \\
\text { integer }\end{array}$ & [1366] & $\mathrm{N} / \mathrm{A}$ \\
\hline $\begin{array}{l}\text { EVI_Onset_Greenness_Increase } \\
\text { EVI_Onset_Greenness_Maximum }\end{array}$ & EVI units & & {$[-10,000,10,000]$} & $10^{4}$ \\
\hline EVI_Growing_Season_Area & ¿EVI & & {$[-3660,3660]$} & $10^{2}$ \\
\hline Phenology_Quality & $\mathrm{N} / \mathrm{A}$ & $\begin{array}{l}8 \text { bit } \\
\text { signed }\end{array}$ & Bit fields & $\mathrm{N} / \mathrm{A}$ \\
\hline
\end{tabular}

To illustrate a potential application of these data, Fig. 1 shows the mean growing season length for North America for the period 20012006 derived from MLCD data. To generate this figure, the growing season length for each pixel in each year was calculated as the difference between the time of onset of EVI increase and the time of onset of EVI minimum. Because growing season length is an important variable that affects the time period during which photosynthesis takes place, information derived from the MLCD product is useful for understanding how seasonal and interannual climate forcing affects plant growth, and by extension, gross and net ecosystem exchange over large scales. Recently, Medvigy et al. (2009) and Richardson et al. (in press) have demonstrated the utility of MLCD data for modelbased and empirical studies of seasonal-scale carbon budgets, respectively. In Section 3.3 we present sample results quantifying the nature and magnitude of interannual variability in growing season length for North America based on the MLCD product.

The C5 MLCD product is distributed as separate science data sets (SDS) within a single file stored in Hierarchical Data Format. All SDS layers are produced at $500-\mathrm{m}$ spatial resolution in the MODIS sinusoidal projection. The product includes eight SDSs, which are summarized in Table 1. Note that vegetation can have more than one growth cycle during any 12-month period. Each SDS field therefore includes two 16-bit values, one for each of two possible cycles in a 12month period. To accommodate differences in northern and southern hemisphere seasonality, the MLCD product is created at six-month time steps.

As we indicated above, vegetation growth cycles are estimated using MODIS EVI data. However, rather than using the standard MODIS EVI product (Huete et al., 2002), the MLCD product is generated using EVI computed from MODIS nadir bidirectional reflectance distribution function (BRDF)-adjusted reflectance (NBAR) data (Schaaf et al., 2002). In Collection 5, NBAR data is produced at 500-m spatial resolution and 8-day time steps based on overlapping 16-day periods. The effects of clouds, variable view angles, and atmospheric aerosols are minimized in NBAR data. The EVI is used because it provides greater dynamic range than the normalized difference vegetation index (Huete et al., 2002).

The NBAR product also provides a snow and ice flag in its quality assurance field, indicating whether the data are acquired over a snowcovered or snow-free surface. This information is critical to our approach, as the presence of snow lowers EVI values during the winter months (Delbart et al., 2006; Dye \& Tucker, 2003). In addition, we utilize the 1-km C5 MODIS land surface temperature (LST) product, also available at 8-day time intervals (Wan et al., 2002). At each pixel and time step, EVI values identified to contain snow are replaced with a background EVI value, which is defined as the most recent snow-free EVI value. Gaps caused by clouds and atmospheric aerosols are filled using a centered three-date moving window average. As a final step, the EVI time series are smoothed using a local median-value movingwindow technique (Zhang et al., 2006). This last step has the effect of 


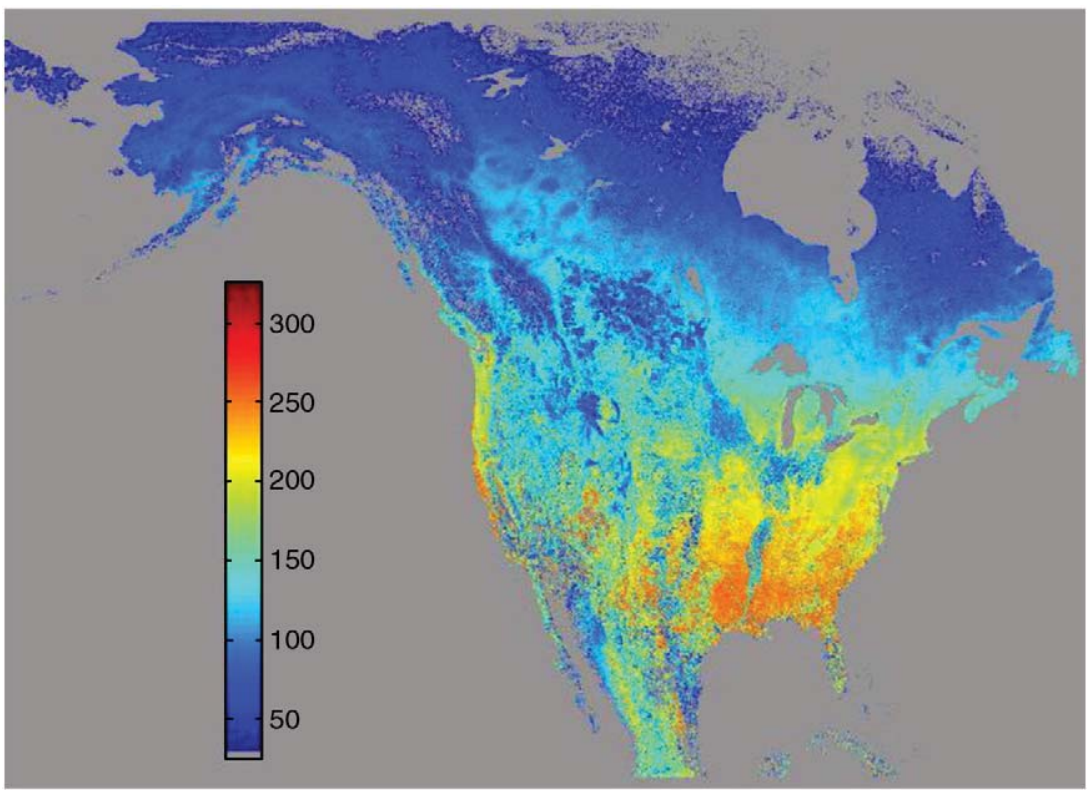

Fig. 1. Mean growing season length in days for North America for the period 2001-2006 derived from the MLCD product.

smoothing the time series by removing EVI values that depart substantially from the local trend in the time series.

\subsection{Algorithm overview}

The MLCD algorithm is described in Zhang et al. (2006). Here we provide a summary of the algorithm. Periods with sustained EVI increase and decrease are determined using moving windows composed of five 8-day NBAR EVI values. Because small decreases or increases can be caused by local or transient processes unrelated to growth cycles, two heuristics are used to exclude such variation: (1) the change in EVI within any period of EVI increase or decrease must be larger than 35\% of the annual range in EVI for that pixel; and (2) the ratio of the local maximum EVI to the annual maximum EVI should be at least 0.7 . This approach screens out short-term variation in EVI unrelated to growth or senescence cycles (Zhang et al., 2006).

Following Zhang et al. (2003), temporal variation in EVI for a single growth or senescence cycle is modeled using a sigmoid function of the form:

$E V I(t)=\frac{c}{1+e^{a+b * t}}+d$

Where $t$ is time in days, $a$ and $b$ are fitted parameters that are estimated using a non-linear least squares algorithm, $c$ is the amplitude of EVI variation, and $d$ is the minimum snow-free EVI value at each pixel. The latter value is defined as the minimum stable value without snow present in the pixel. Using this framework, phenological transition dates are identified based on the rate of change in curvature of the fitted logistic models at each pixel (Zhang et al., 2003, 2006). In addition, the algorithm computes the growing season integrated NBAR EVI (the sum of the modeled daily EVI values from the onset of EVI increase to the onset of EVI minimum), and records the EVI values corresponding to the transition dates in the modeled EVI time series. Key differences relative to the C4 product are that (1) C5 is produced at $500-\mathrm{m}$ spatial resolution based on 8-day instead of 16-day periods; (2) the input EVI data benefit from refinements to upstream products (surface reflectance and NBAR data); and (3) the algorithm no longer applies a 3 by 3 moving window average at each pixel to remove high frequency spatial variance. Thus, the spatial resolution of the product has increased from an effective spatial resolution of $3-\mathrm{km}$ to $500-\mathrm{m}$.

\section{Analysis and results}

In this section we present results from four different sets of analysis. Because a global comparison is not practical, we present results for six MODIS tiles (h23v02, h12v03, h12v04, h27v05, h20v07, and h20v08) encompassing a wide range of climate and land cover types (Fig. 2). Hereafter, we refer to these as the subarctic Eurasian, boreal North American, temperate North American, temperate Asian, arid tropical, and humid tropical tiles, respectively. These tiles include tundra, boreal, temperate, sub-tropical and tropical climate regimes, and encompass biome types that span the entire range of temperature and moisture-limited life forms. Two of these tiles include regions with substantial human management of land cover and land use. All of the IGBP land cover types are included in this sample. With the exception of the IGBP closed shrublands (which is a small class), water, urban, and permanent snow and ice classes, each IGBP class is included as one of three dominant classes in one or more of these tiles (Table 2).

We use these tiles throughout the analysis presented in Sections 3.1, 3.2, and 3.3. We begin in Section 3.1 by characterizing the nature and magnitude of missing data in the C5 MLCD product. In Section 3.2 we present a comparison of the MLCD product for C4 versus C5. The goal of this analysis is to provide a qualitative and quantitative assessment of differences and similarities between the two versions of the product. In Section 3.3, we examine C5 MLCD results across different years and assess the nature and magnitude of interannual variation in $\mathrm{C} 5$ data sets. Finally, in Section 3.4 we compare results from the $\mathrm{C} 4$ and $\mathrm{C} 5$ products against ground data from two sites, which provides a quantitative assessment of the MLCD product quality relative to phenology measured on the ground. In Sections 3.2 and 3.3 the 1-km C4 land cover dynamics product is used as a benchmark for comparison with the C5 product. To allow this comparison, C4 data were resampled to $500-\mathrm{m}$ using bi-cubic interpolation. The phenological metrics produced by the MLCD algorithm are the same for both C4 and C5, and aside from different input data and spatial resolutions, are directly comparable. The MODIS C5 global land cover type map (MCD12Q1; Friedl et al., 2010) is also used in this exercise to stratify the data into different land cover classes. 


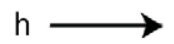

$\begin{array}{llllllllllllllllllllllllllllllllllll}0 & 1 & 2 & 3 & 4 & 5 & 6 & 7 & 8 & 9 & 10 & 11 & 12 & 13 & 14 & 15 & 16 & 17 & 18 & 19 & 20 & 21 & 22 & 23 & 24 & 25 & 26 & 27 & 28 & 29 & 30 & 31 & 32 & 33 & 34 & 35\end{array}$

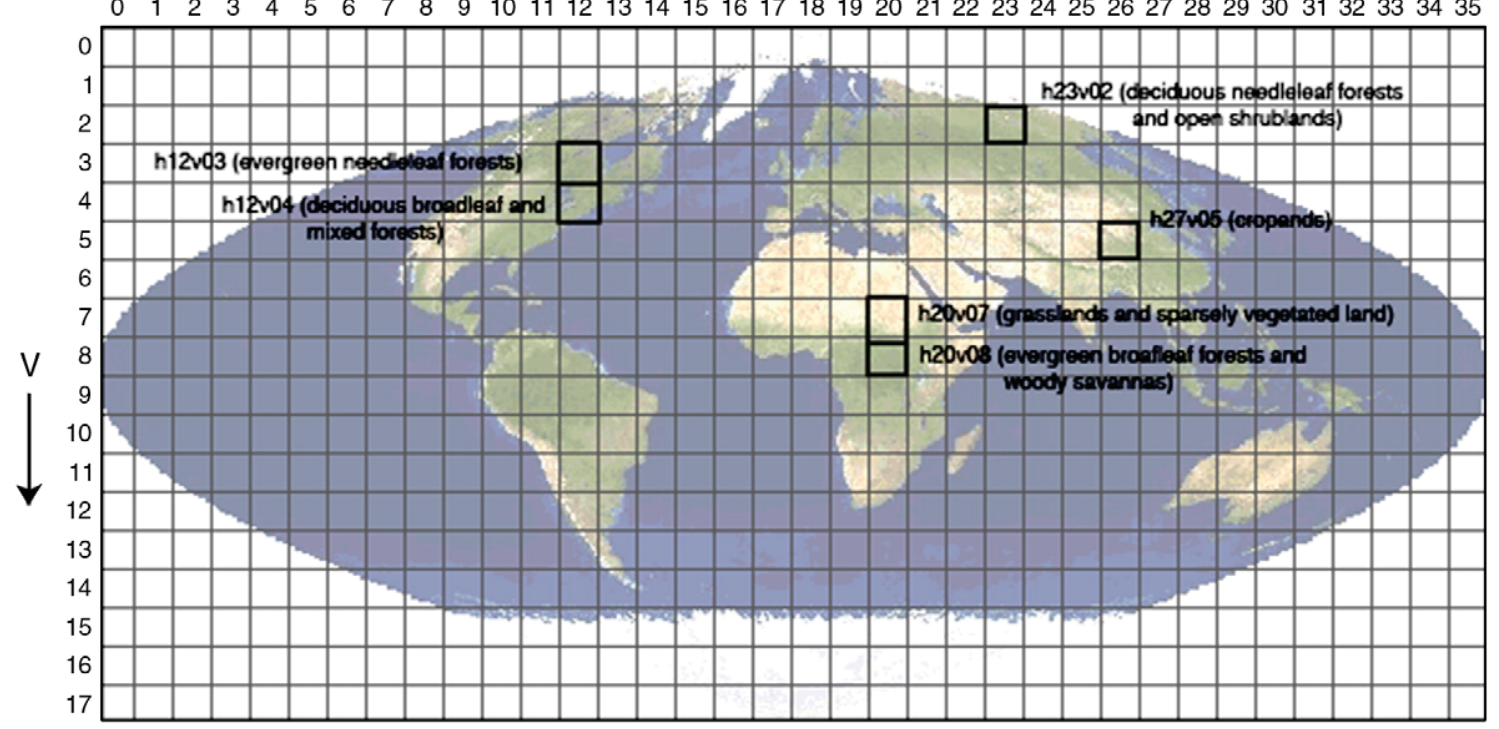

Fig. 2. Global sinusoidal MODIS tile map displaying the six tiles (solid black boxes) that are used in the analysis. The labels classify these tiles according to the dominant land cover type in each tile from the MODIS Land Cover Type product.

\subsection{Missing data}

We first explore the nature and magnitude of missing input data in C5 MLCD results relative to C4. The C4 product was produced for 2001 through 2004 and the $C 5$ product spans the time period from 2001 to present. Here we consider data from 2002 from each collection. Before addressing the more general question of missing values arising from clouds, atmospheric aerosols, and low illumination conditions we first discuss a specific issue. In 2001, instrument problems on the TerraMODIS sensor from day-of-year (DOY) 166 (June 15) to DOY 183 (July 2) resulted in a data gap during a critical period of the northern hemisphere growing season. As a consequence, the quality of MLCD retrievals during this period was significantly compromised in C4. In C5, MLCD input data for DOY 166-183 in 2001 were imputed using mean NBAR data for the same period from 2002 to 2006 at each pixel. Fig. 3 shows the original EVI time series and the gap-filled data for a pixel in central Massachusetts and illustrates the effectiveness of this solution. Prior to applying this adjustment, noticeable artifacts were present in MLCD results throughout the northern hemisphere. Visual inspection of C5 results confirms that this strategy removes the majority of these artifacts, which were also present in C4 data. That said, MLCD values during this period are necessarily of modestly lower quality relative to other time periods.

More generally, missing values caused by clouds and aerosols are a major source of uncertainty in MLCD results (Zhang et al., 2009). However, because the 8-day C5 MODIS reflectance data provide higher frequency data with better cloud screening and atmospheric correction relative to $\mathrm{C} 4$, the $\mathrm{C} 5$ product has fewer missing values relative to $\mathrm{C} 4$. To illustrate, Fig. 4 shows the proportion of missing retrievals for greenup onset dates in C5 and C4 in 2002 for each of the six tiles shown in Fig. 2. Fig. 4 shows that $\mathrm{C} 5$ data have substantially fewer missing retrievals for the subarctic Eurasian, boreal North

Table 2

Summary statistics (mean, standard deviation) for MLCD SDS's in each of the selected tiles, stratified by the three dominant land cover types in each. LC types are IGBP land cover classes from the MCD12Q1 product: 1. Evergreen needleleaf forest; 2: evergreen broadleaf forest; 3 deciduous needleleaf forest; 4 : deciduous broadleaf forest; 5 : mixed forest; 7: open shrublands; 8: woody savannas; 9 savannas; 10: grasslands; 11: wetlands; 12 agriculture; 14: agricultural mosaic; 16: barren and sparsely vegetated.

\begin{tabular}{|c|c|c|c|c|c|c|c|c|c|c|c|c|c|c|c|c|c|}
\hline \multirow[t]{2}{*}{ Tile ID } & \multirow[t]{2}{*}{$\begin{array}{l}\text { LC } \\
\text { type }\end{array}$} & \multirow[t]{2}{*}{$\begin{array}{l}\text { Pixels } \\
\left(\times 10^{4}\right)\end{array}$} & \multirow[t]{2}{*}{$\% \mathrm{LC}$} & \multicolumn{2}{|c|}{$\begin{array}{l}\text { Onset EVI } \\
\text { Increase }\end{array}$} & \multicolumn{2}{|c|}{$\begin{array}{l}\text { Onset EVI } \\
\text { Maximum }\end{array}$} & \multicolumn{2}{|c|}{$\begin{array}{l}\text { Onset EVI } \\
\text { Decrease }\end{array}$} & \multicolumn{2}{|c|}{$\begin{array}{l}\text { Onset EVI } \\
\text { Minimum }\end{array}$} & \multicolumn{2}{|c|}{ Integrated EVI } & \multicolumn{2}{|c|}{ Maximum EVI } & \multicolumn{2}{|c|}{ Minimum EVI } \\
\hline & & & & $\overline{\mathrm{x}}$ & $\sigma$ & $\overline{\mathrm{x}}$ & $\sigma$ & $\overline{\mathrm{x}}$ & $\sigma$ & $\overline{\mathrm{x}}$ & $\sigma$ & $\overline{\mathrm{X}}$ & $\sigma$ & $\overline{\mathrm{x}}$ & $\sigma$ & $\overline{\mathrm{x}}$ & $\sigma$ \\
\hline \multirow{3}{*}{ Subarctic Eurasia } & 3 & 241.01 & 43 & 141 & 5 & 179 & 5 & 219 & 3 & 255 & 3 & 38.86 & 1.14 & 0.42 & 0.0038 & 0.20 & 0.0060 \\
\hline & 7 & 194.96 & 35 & 157 & 5 & 189 & 4 & 219 & 4 & 246 & 2 & 28.18 & 0.76 & 0.36 & 0.0036 & 0.23 & 0.0057 \\
\hline & 8 & 89.90 & 16 & 151 & 5 & 187 & 4 & 220 & 4 & 249 & 2 & 28.09 & 0.97 & 0.34 & 0.0046 & 0.19 & 0.0058 \\
\hline \multirow[t]{3}{*}{ Boreal North America } & 1 & 255.90 & 48 & 135 & 11 & 188 & 7 & 219 & 6 & 268 & 3 & 39.75 & 3.51 & 0.35 & 0.0046 & 0.22 & 0.0062 \\
\hline & 11 & 100.82 & 19 & 136 & 12 & 192 & 7 & 224 & 5 & 271 & 3 & 42.26 & 4.44 & 0.37 & 0.0053 & 0.23 & 0.0060 \\
\hline & 4 & 55.59 & 10 & 138 & 12 & 192 & 8 & 223 & 6 & 269 & 2 & 42.02 & 4.15 & 0.38 & 0.0057 & 0.23 & 0.0048 \\
\hline \multirow[t]{3}{*}{ Temperate North America } & 5 & 168.07 & 40 & 130 & 4 & 177 & 5 & 221 & 2 & 286 & 4 & 68.75 & 2.12 & 0.55 & 0.0059 & 0.27 & 0.0097 \\
\hline & 4 & 92.64 & 22 & 117 & 3 & 163 & 4 & 223 & 1 & 304 & 3 & 100.15 & 3.28 & 0.70 & 0.0132 & 0.27 & 0.0118 \\
\hline & 14 & 79.62 & 19 & 109 & 3 & 171 & 2 & 223 & 3 & 303 & 2 & 93.09 & 2.72 & 0.62 & 0.0114 & 0.25 & 0.0091 \\
\hline \multirow[t]{3}{*}{ Arid Tropical } & 16 & 299.15 & 52 & 212 & 11 & 230 & 9 & 249 & 7 & 254 & 16 & 9.67 & 1.07 & 0.14 & 0.0100 & 0.09 & 0.0009 \\
\hline & 10 & 164.67 & 29 & 182 & 9 & 232 & 6 & 255 & 6 & 287 & 9 & 32.79 & 2.62 & 0.33 & 0.0136 & 0.15 & 0.0041 \\
\hline & 7 & 55.34 & 9 & 186 & 6 & 230 & 6 & 252 & 5 & 277 & 8 & 30.69 & 2.27 & 0.30 & 0.0091 & 0.14 & 0.0028 \\
\hline \multirow[t]{3}{*}{ Humid Tropical } & 2 & 225.98 & 39 & 95 & 14 & 138 & 12 & 178 & 26 & 183 & 33 & 89.66 & 26.13 & 0.58 & 0.0180 & 0.30 & 0.0972 \\
\hline & 8 & 202.73 & 35 & 60 & 5 & 186 & 3 & 251 & 6 & 276 & 42 & 124.47 & 4.04 & 0.58 & 0.0050 & 0.26 & 0.0101 \\
\hline & 9 & 126.95 & 22 & 106 & 6 & 211 & 3 & 252 & 2 & 307 & 16 & 92.64 & 2.15 & 0.57 & 0.0048 & 0.20 & 0.0098 \\
\hline \multirow[t]{3}{*}{ Temperate Asia } & 12 & 267.03 & 59 & 120 & 17 & 163 & 13 & 188 & 10 & 229 & 7 & 38.37 & 4.90 & 0.46 & 0.0162 & 0.11 & 0.0351 \\
\hline & 5 & 58.96 & 13 & 92 & 11 & 155 & 2 & 209 & 3 & 277 & 9 & 82.75 & 6.05 & 0.59 & 0.0161 & 0.17 & 0.0183 \\
\hline & 14 & 47.72 & 10 & 113 & 11 & 168 & 7 & 207 & 8 & 250 & 14 & 55.38 & 3.81 & 0.52 & 0.0207 & 0.12 & 0.0158 \\
\hline
\end{tabular}




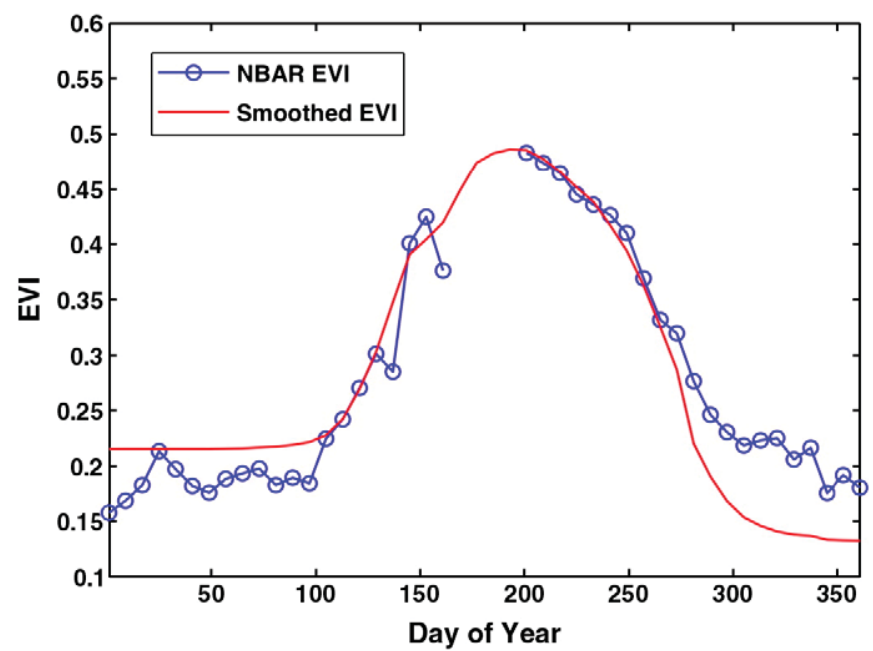

Fig. 3. Sample time series for a pixel in central Massachusetts showing the original EVI time series for 2001 including the data gap in late June and early July (blue), and the 2002-2006 mean EVI for the same period used to fill the missing data. Note that only data from the missing period were replaced. The rest of the time series is shown for completeness.

American, temperate North American, and temperate Asian tiles. For the other two tiles the proportion of missing data is comparable $(\sim 40-50 \%)$, but is slightly higher in C5 relative to C4. This result reflects the fact that areas in the tropics and Asia are characterized by persistent cloud cover, high levels of atmospheric aerosols, or weak seasonality, all of which present substantial challenges for land surface phenology algorithms. To avoid generating spurious results, the MLCD algorithm is designed to be conservative and does not produce a result if data are missing during transition periods or if the amplitude in seasonal EVI is very low. This results in high levels of missing values in parts of the tropics and subtopics, and in areas with persistent high aerosol loading. In the specific case of the tiles examined here, land cover in the humid tropical and arid tropical tiles includes $39 \%$ evergreen broadleaf forest and 52\% barren and sparsely vegetated land cover, respectively. Thus, the relatively high percentage of missing values in these tiles is neither surprising nor inappropriate. In the temperate Asian tile, there are fewer missing values in C5, but the overall rate is still high. Land cover in this tile is

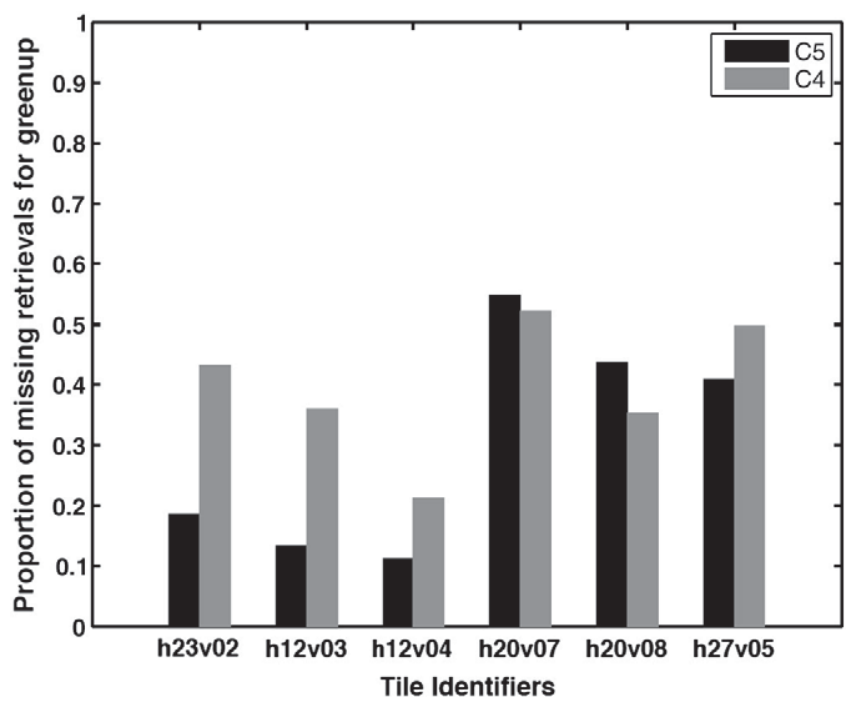

Fig. 4. Proportion of missing retrievals for onset of EVI increase dates from the C5 and C4 products for 2002 . dominated by agriculture and mixed forests and the high percentages of missing values is related to persistent cloud cover and atmospheric aerosols in this region of Asia.

\subsection{Comparison with Collection 4 MLCD data}

We now present a comparison of the MLCD products for C5 and C4. Fig. 5 presents images showing retrieved transition dates for $\mathrm{C} 5$ (year 2002) corresponding to the onset time of EVI increase, maximum, decrease, and minimum for the six MODIS tiles used in our analysis. To save space, here we present results from 2002 only. To assess the representativeness of 2002 results, we performed parallel analyses for 2003-2006. No substantial differences were observed across years during this time period and we therefore concluded that presentation of results for 2002 is sufficient for the goals of this comparison.

Fig. 6 shows frequency distributions for differences in transition dates for 2002 (C5 minus C4) for the six MODIS tiles identified above. Only pixels with valid retrievals in both data sets were included. Differences between C4 and C5 are generally within \pm 50 days. Indeed, most differences were of much smaller magnitude, and some differences are introduced by resampling the $1-\mathrm{km}$ C4 data to $500-\mathrm{m}$ spatial resolution. However, the arid subtropical and humid tropical tiles show substantial differences in the timing of onset of EVI increase. Specifically, while the primary mode of the distribution is close to zero, there is a clear secondary mode in both tiles associated with later greenup dates in C5 compared to C4. Unfortunately, C4 NBAR data are no longer available for comparison. Fig. 7 presents the mean C5 EVI profile ( \pm 1 standard deviation) for pixels in the humid tropical tile where the difference in timing is between 30 and 70 days. This figure shows that the C5 result is reasonable, and that the algorithm may have been spuriously detecting early season greening in C4.

Fig. 8 presents scatterplots showing mean transition dates for IGBP land cover types in C5 versus C4 for 2002. The class means are in close agreement for most tiles. The humid tropical tile shows substantial disagreement in the average date of onset for EVI decrease and EVI minimum for several classes (evergreen broadleaf and deciduous broadleaf forests, woody savannas, and mixed forests). Overall, however, the comparisons presented in Figs. 6 and 8 indicate that despite differences in the spatial and temporal resolution in each collection, results from each of the products are generally quite consistent, with some explainable discrepancies in the tropics.

\subsection{Interannual variability with land cover}

In this section, we characterize the nature and magnitude of variability in C5 phenological metrics at interannual time scales from 2001 to 2006. Table 2 presents summary statistics where, for each of the three most common classes in each tile, we present the overall mean value for each SDS listed in Table 1 (excluding phenology quality), along with corresponding standard deviations. The patterns in average phenology revealed in this table are consistent with expected biogeographic patterns: the timing and length of the growing season varies with climate and land cover, with unmanaged temperate and humid tropical land cover types showing longer growing seasons and higher overall greenness than high-latitude, arid tropical, and managed land cover types.

Closer inspection of Table 2 reveals a number of patterns that merit further attention. Specifically, depending on geographic location, land cover exerts strong control on phenology. For example, the onset of EVI increase for IGBP classes 3 (subarctic Eurasia), 5 (temperate North America), 16 (arid subtropical), and 8 (humid tropical) are quite different from neighboring land cover types in these tiles. The onset of EVI minimum also shows substantial dependence with land cover (e.g., class 16 in the arid subtropical tile and all three classes for the humid subtropical and temperate Asian tiles). With relatively few 


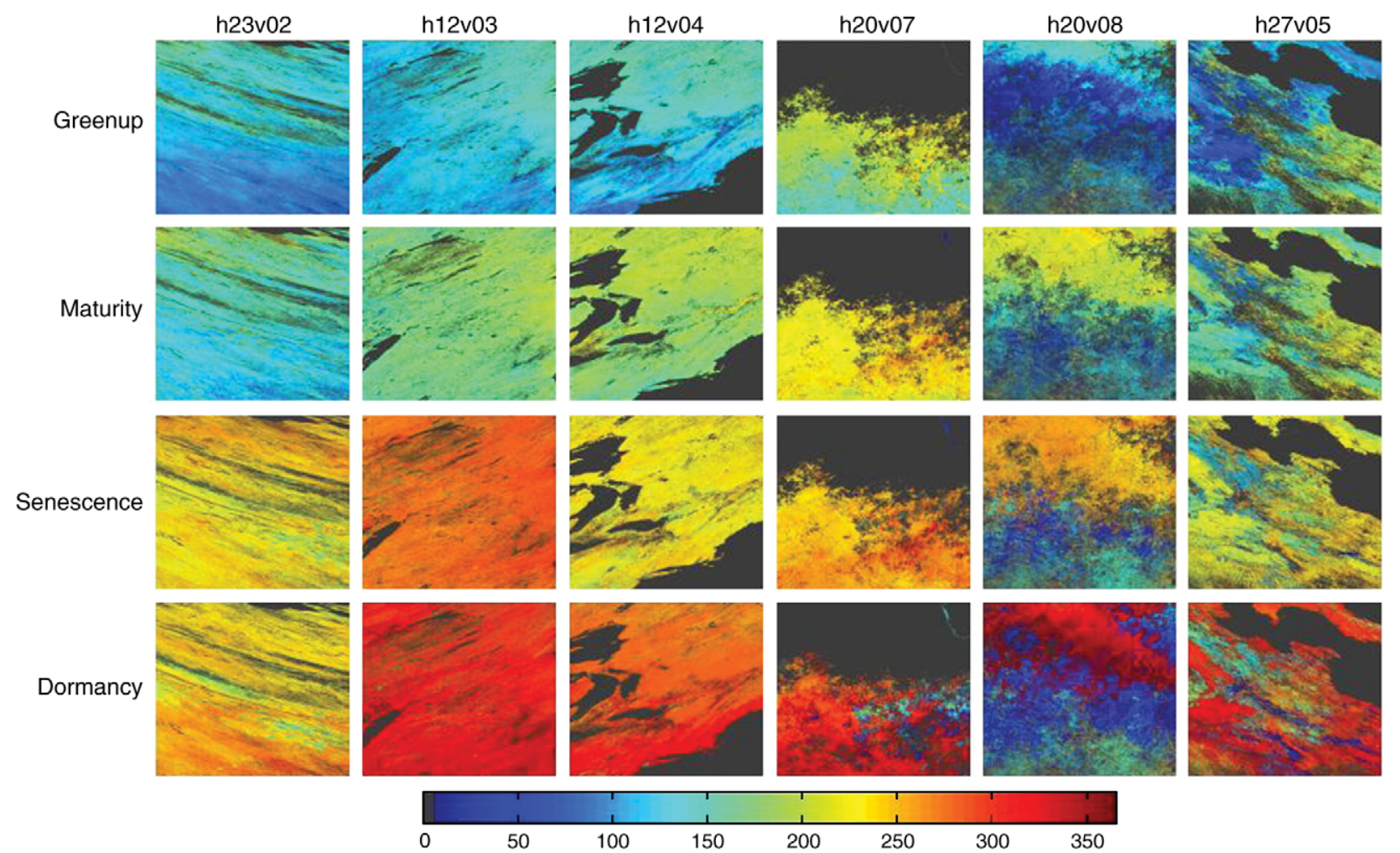

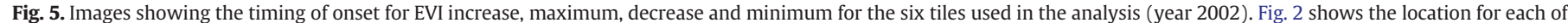
these tiles.
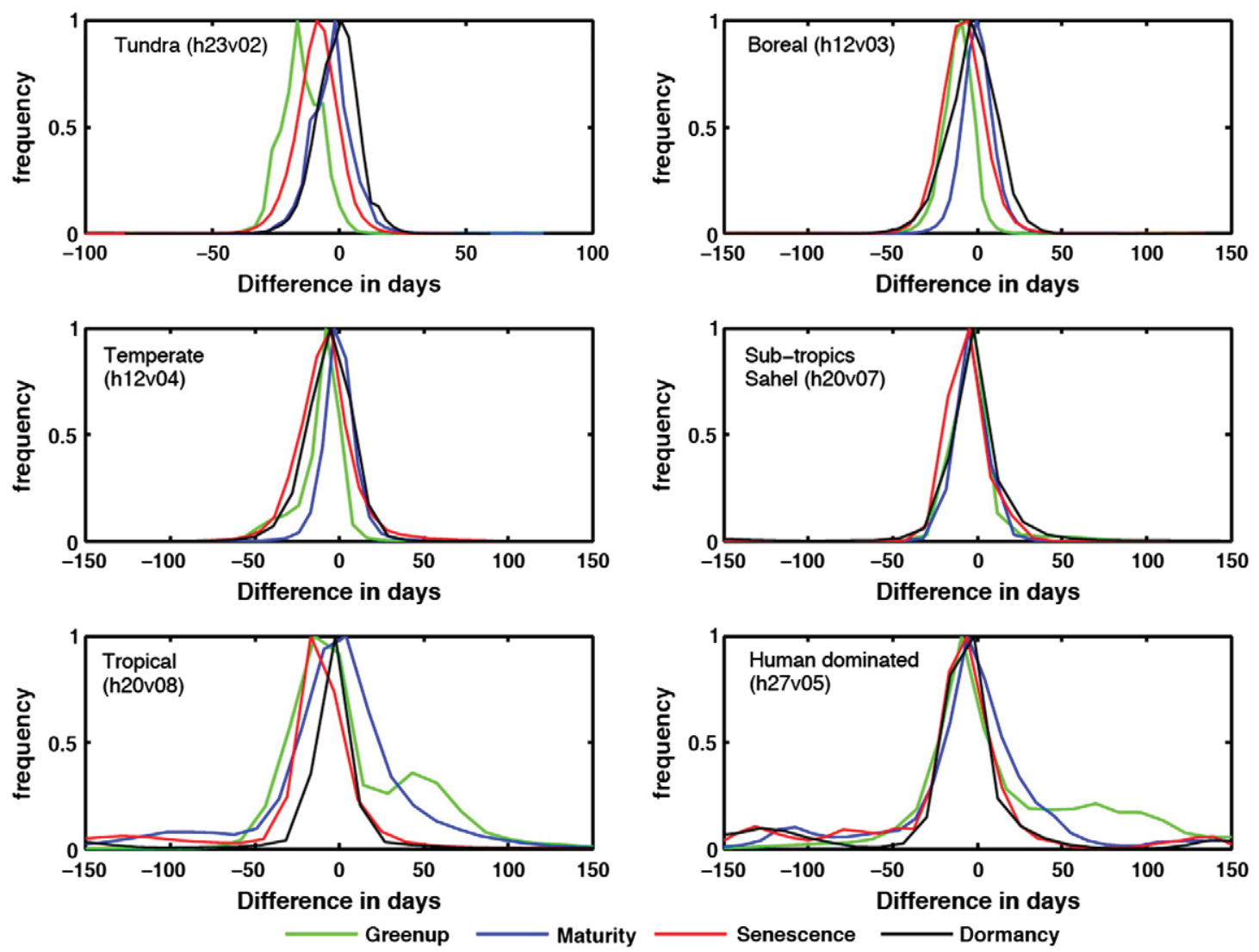

Fig. 6. Frequency distributions for differences between the C5 and C4 Land Cover Dynamics products at 500-m spatial resolution. Note that the distributions have been normalized to scale from 0 to 1 . 


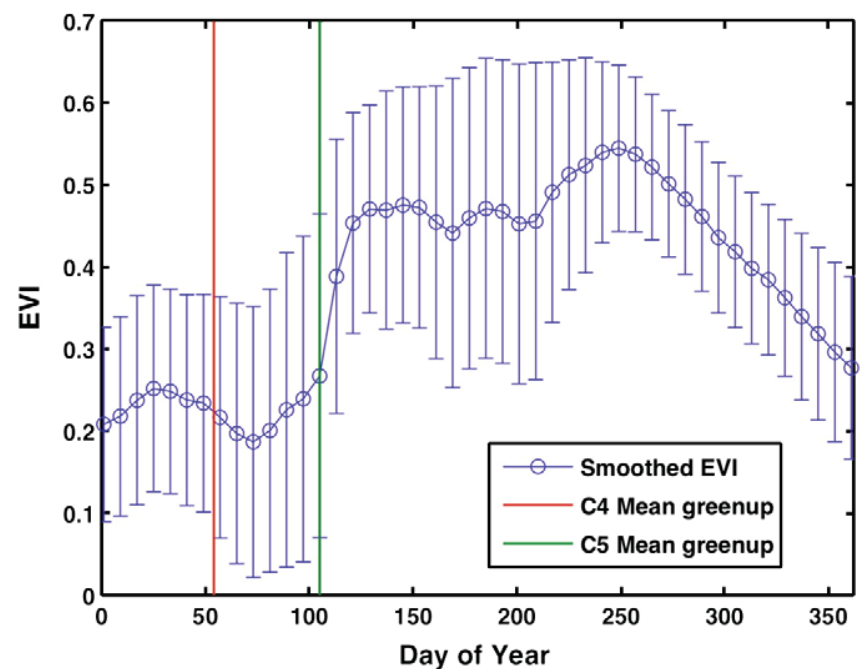

Fig. 7. Mean ( \pm 1 standard deviation) EVI time series for pixels in tile h20v08 where C5 greenup onset is between 30 and 70 days after C4 greenup.

exceptions, average timing in the onset of EVI maximum and the onset of EVI decrease are generally quite uniform within classes.

Equally important, the magnitude of interannual variability (i.e., standard deviations) in transition dates varies strongly with land cover. Year-to-year variability is relatively high for the onset of EVI increase in the boreal North American and temperate Asian tiles, and for the onset of EVI minimum in the humid tropical tile. Individual classes in specific tiles (e.g., class 2 in the humid tropical tile) also show large standard deviations. High variance in the onset of EVI increase in the temperate Asian tile is largely associated with agricultural land use. In the case of the North American boreal tile, which is dominated by the boreal forest biome, variability introduced by fires and regional "browning" trends may partly explain this pattern (Bunn \& Goetz, 2006; Soja et al., 2007). More generally, large variance in the timing of phenology corresponds to classes and locations that present the greatest challenges for remote sensing: evergreen systems (classes 1,2 ), locations with high percentages of missing input data (i.e., the temperate Asian and humid tropical tiles), and locations at high latitudes with low solar zenith angles and heterogeneous landscapes (boreal North America). Surprisingly, the subarctic Eurasian tile shows relatively low levels of variability in the timing of phenology within classes, which probably reflects the strong control that synoptic temperature patterns exert on phenology in this region.

Variability in integrated EVI for class 2 in the humid tropical tile is an order of magnitude larger than for any other class or tile. This result reflects difficulties involved in remote sensing of phenology for evergreen tropical ecosystems. Several recent studies have demonstrated both the utility and challenges of remote sensing for studying tropical phenology (e.g., Huete et al., 2006; Myneni et al., 2007). The variability in integrated EVI for class 2 in this tile reflects this
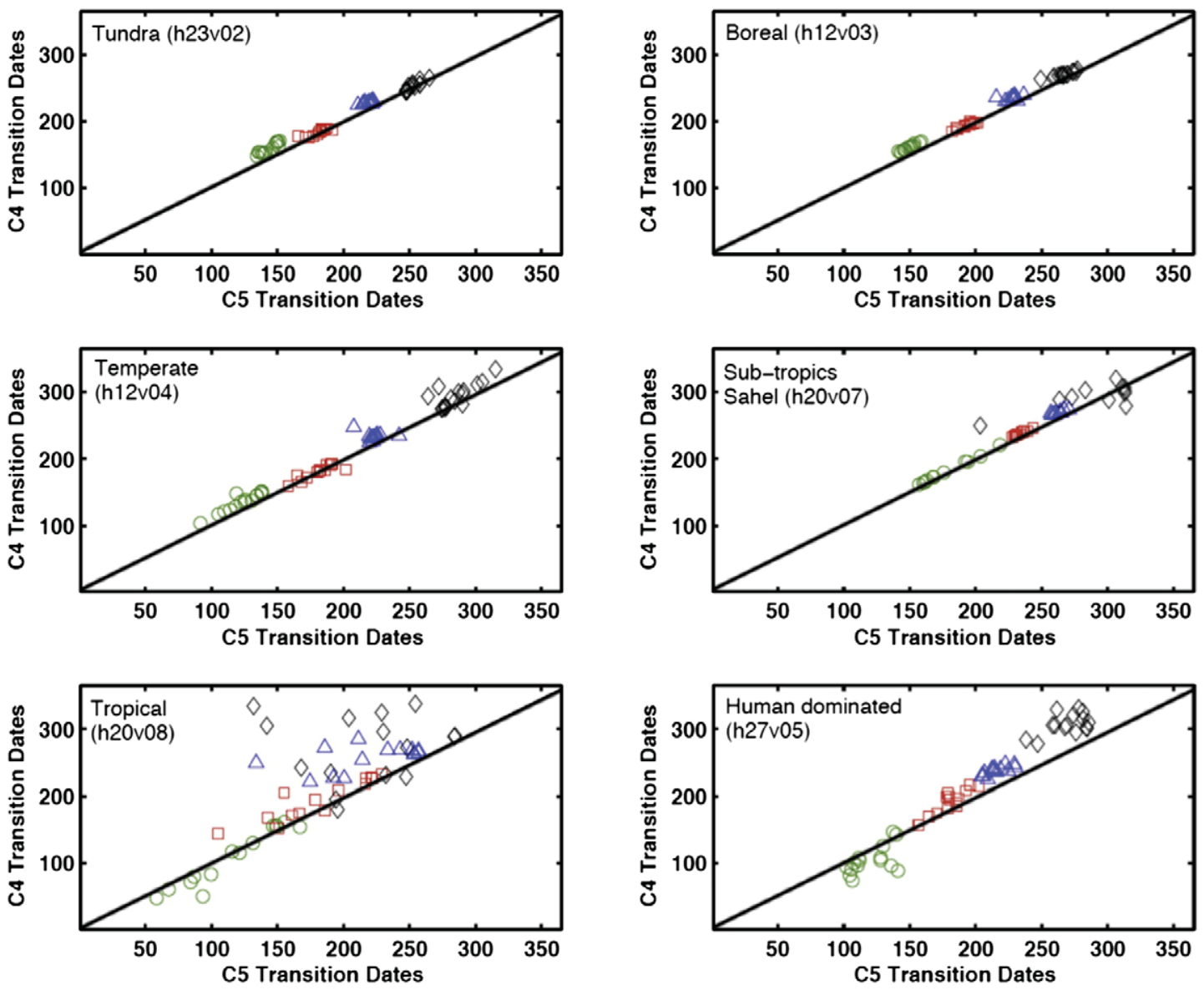

Greenup $\square \quad$ Maturity

$\triangle$ Senescence $\diamond$ Dormancy

Fig. 8. Mean transition dates for different land cover classes in the C5 and C4 MLCD products. The mean values are computed for each land cover type present in each tile obtained from the C5 MODIS Land Cover Type product. 
challenge and also suggests that MLCD results are probably less reliable for tropical evergreen ecosystems.

Finally, to illustrate the nature and magnitude of geographic patterns in interannual variability captured by the C5 MLCD product, Fig. 9 shows a map of anomalies in the timing of EVI increase and growing season length for 2002 relative to 2001-2006 averages (computed as 2002 minus the multi-year average), along with histograms for each. This figure suggests that the onset of green-up occurred later over much of North America relative to the 2001-2006 average, especially at mid- to high latitudes and in the south-central United States. With the exception of the southeastern region, growing season anomalies follow the same general pattern and are positive (i.e., shorter growing season) throughout much of the continent. The climatic forcing behind this pattern is unclear, but it is likely that the widespread Northern Hemisphere drought that extended into 2002 provides a partial explanation (Lotsch et al., 2005).

\subsection{Assessment using field data}

Validation of moderate resolution satellite products using ground measurements is challenging for several reasons including difficulties scaling plot level measurements to the resolution of the sensor field of view, geo-location uncertainties, limited temporal and spatial sampling of ground data, field instrument calibration, and sampling errors (Buermann et al., 2002; Herold et al., 2008; Huang et al., 2006; Tan et al., 2005a,b; Weiss et al., 2007). In addition to being relatively sparse, available field measurements related to phenology are normally collected for individual plants at scales well below the resolution of moderate spatial resolution sensor like MODIS. Further, the field of view of NBAR data generally includes a mosaic of species and landcover types (Baccini et al., 2008; Morisette et al., 2002). This presents significant challenges for product assessment and validation using measurements collected on the ground.

In the specific case of the MLCD product, comparison between MODIS phenology and in-situ values is challenging for at least three reasons. First, the location of MODIS pixels and ground data may not match because of geo-location uncertainties (Tan et al., 2006). Second, the MODIS MLCD algorithm generates values for transition dates from NBAR EVI time series, which include uncertainties introduced by imperfect atmospheric correction, the presence of snow, cloud cover, and the 8-day temporal resolution of the EVI data. This issue is important because we are specifically interested in comparing events measured in time on the ground with estimated transition dates from the MLCD product, and best practices for achieving this goal are the subject of ongoing debate in the community (e.g., Schwartz \& Hanes, 2009; White et al, 2009). Third, in-situ measurements for a particular field site may not be representative of the associated 500-m MODIS pixel (Liang \& Schwartz, 2009). Recognizing these limitations, here we compare MLCD results with available field data collected over multiple years from two long-term ecological reserve sites: (1) Harvard Forest in central Massachusetts and (2) Hubbard Brook in the White Mountain National Forest of New Hampshire.

\subsubsection{Comparison with Harvard Forest data}

Forest overstory and understory phenology data have been collected by Harvard Forest staff since 1989 using a consistent
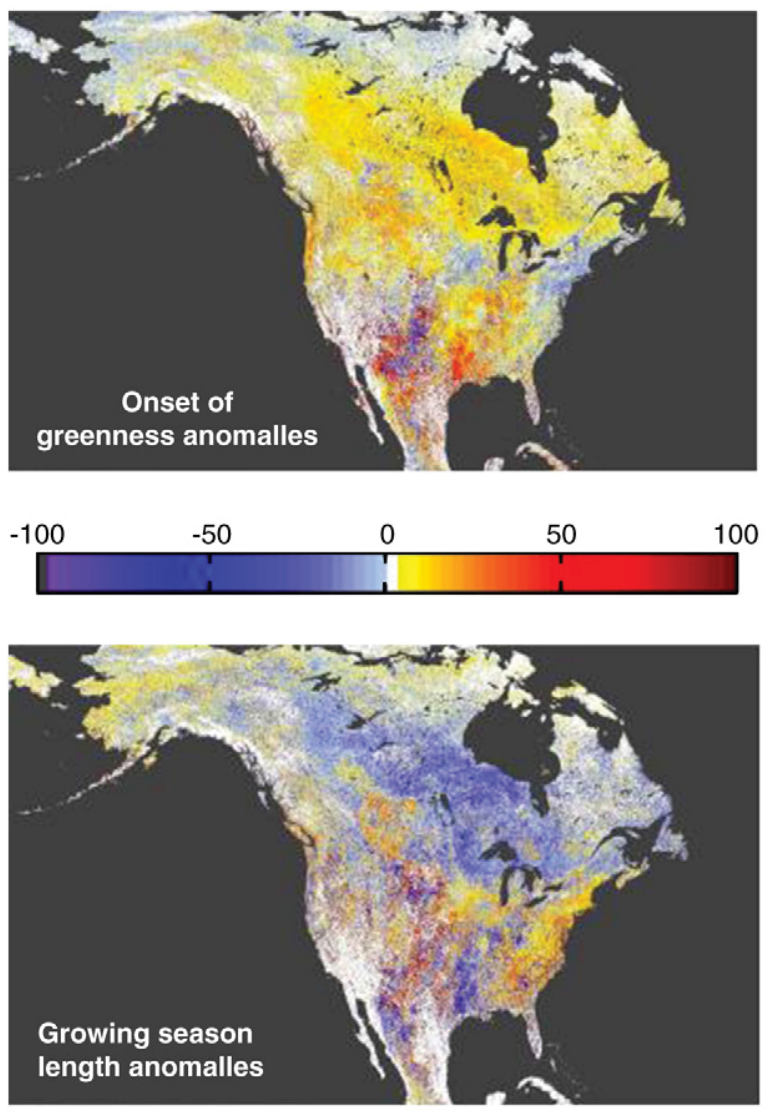
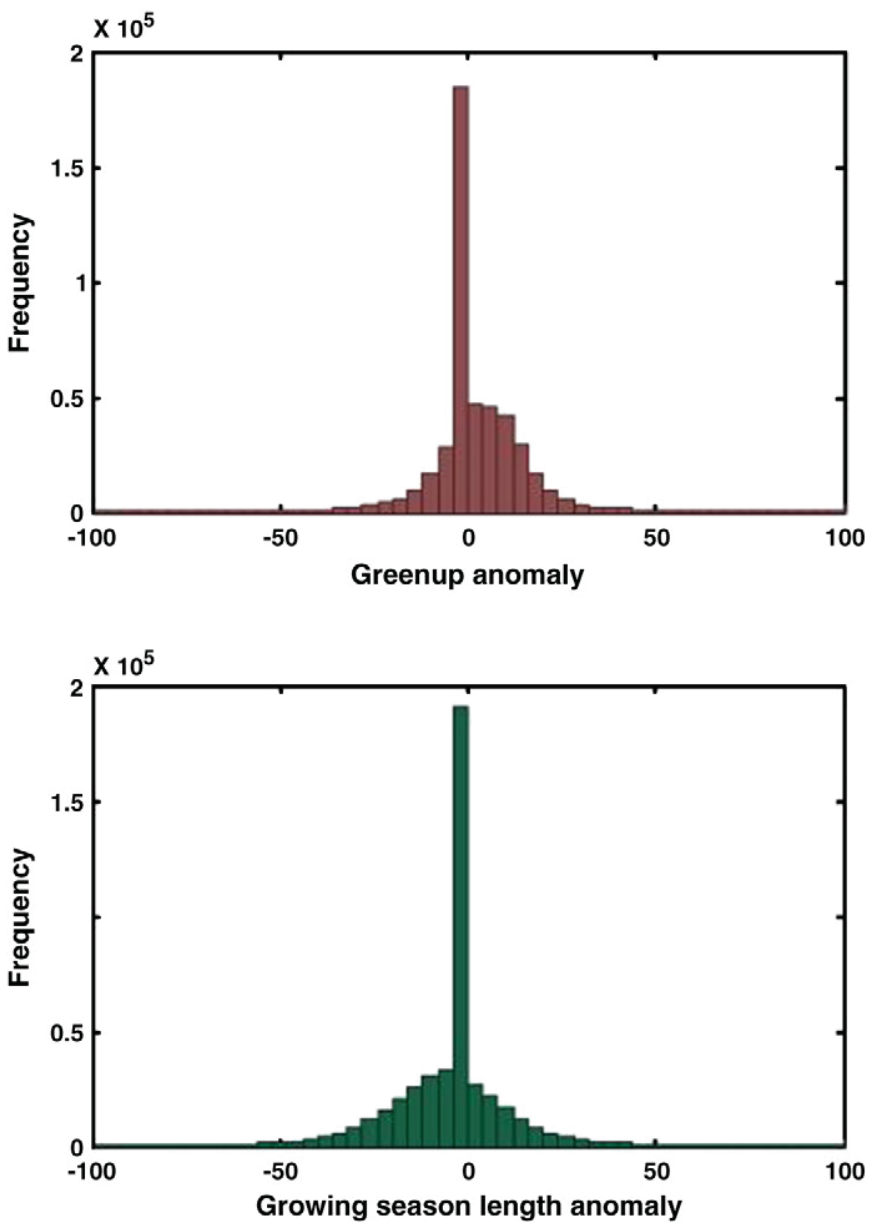

Fig. 9. Anomalies in the timing of greenup onset and growing season length for 2002 relative to the 2001-2006 mean. 
protocol and sampling strategy. Data are collected for two to five individuals of 33 native tree species located along a $2 \mathrm{~km}$ loop near the Harvard Forest headquarters $\left(42^{\circ} 32^{\prime} \mathrm{N}, 72^{\circ} 11^{\prime} \mathrm{W}\right)$. Observations include measurements of percent canopy budburst and leaf development from April to June and percent leaf coloration and leaf drop from September to November at intervals of 3-7 days. Data from Harvard Forest were obtained from the Harvard Forest website (http://www. lternet.edu/hfr/). In this study, we examined data from 2001 to 2006.

Table 3 presents a comparison of ground data collected at Harvard Forest with phenological transition dates estimated from MODIS for the onset timing of EVI increase $\left(G_{O}\right)$, maximum $\left(G_{M}\right)$, decrease $\left(G_{S}\right)$, and minimum $\left(G_{\mathrm{D}}\right)$. Values for MODIS are based on a set of twentyfive C5 500-m MODIS pixels that intersect the ground data collection locations. For comparison, we include results for C4 (2001-2004). Corresponding indices based on ground measurements are also shown and defined in Table 3. Fig. 10 shows the time series of EVI data with mean values for phenological transition dates estimated by the MLCD algorithm at Harvard Forest in 2002.

As we alluded to above, comparison of ground measurements of canopy phenology with MLCD transition dates is challenging. Here we compare continuous measures of canopy development (e.g., percent budburst) acquired at varying time intervals on the ground with MLCD transition dates. Specifically, we compare $G_{O}$ with the percent of the canopy for which budbreak had occurred on the same date; $G_{\mathrm{M}}$ with the percent of the canopy that had achieved $75 \%$ and $95 \%$ of full leaf development; $G_{S}$ with the percent of the canopy with colored leaves and the percent of fallen leaves in the canopy; and $G_{D}$ with the average date of last green leaf in the canopy, and the percent of green leaves in the canopy at the time of $G_{\mathrm{D}}$.

Values corresponding to the average budburst date (BBD) lag C5 MODIS values of $G_{O}$ by about 1-17 days in each of the six years. In general $G_{O}$ values from MODIS correspond to the time when budburst has occurred for 5 to $33 \%$ of the forest canopy, and the range of BBD values in Table 3 includes the corresponding MODIS retrievals in all years except 2001 and 2002, when MODIS values for $G_{O}$ precedes the earliest non-zero value of BBD by 1 and 4 days, respectively. Overall, these results suggest that MODIS estimates of $G_{O}$ are sensitive to the early stages of leaf development at Harvard Forest. Note that MODIS results are also likely sensitive to understory phenology (not included in the data presented in Table 3), which tends to precede that of the forest canopy at Harvard Forest (Richardson \& O'Keefe, 2009).

The range of transition dates for the onset of EVI maximum $\left(G_{\mathrm{M}}\right)$ from MODIS corresponded to the timing when $87-100 \%$ of leaves had reached $75 \%$ of their final size (FL1), and when $72-97 \%$ of leaves had reached 95\% their final size (FL2). These results suggest that the $G_{M}$

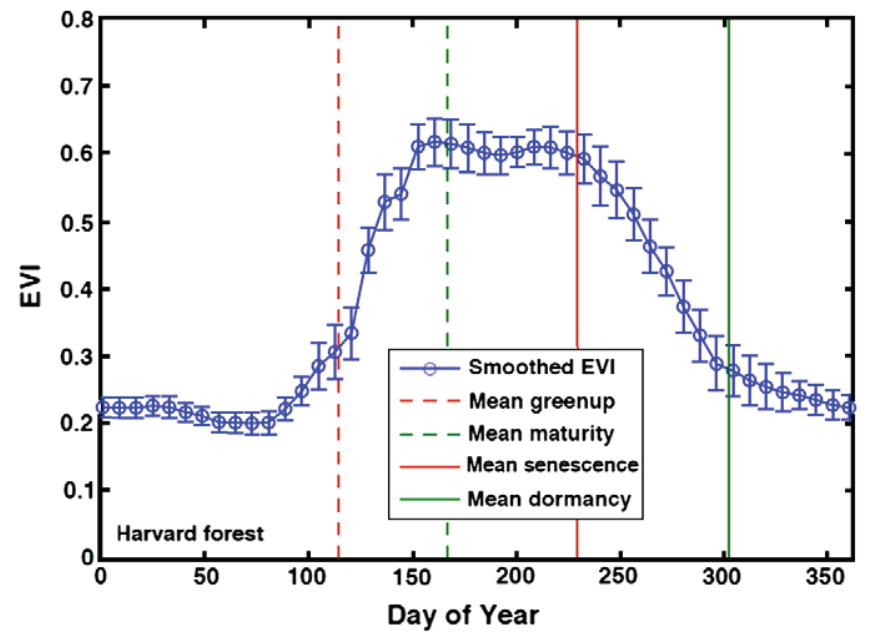

Fig. 10. Time series of mean EVI ( \pm 1 standard deviation $)$ at Harvard forest for 2006 with mean dates for the onset of EVI increase, maximum, decrease and minimum plotted as vertical lines.

values correspond well to the time that maximum canopy development occurs. Note that $G_{O}$ and $G_{M}$ values in 2001 were probably affected by the MODIS instrument problems identified above.

In the fall, average MODIS retrievals for the mean onset time of EVI decrease $\left(G_{S}\right)$ range from DOY 224-241 over the six years considered. During this period the average percentage leaf coloring varied from 0.3 to $1.8 \%$ and the average percentage of leaves that had fallen ranged from 0.1 to $0.8 \%$. Average values for the onset time of EVI minimum $\left(G_{\mathrm{D}}\right)$ retrieved from MODIS differ from the average date of last green leaf coloring (AGD) by about 20 days. This result suggests that MLCD values for $G_{D}$ are biased late relative to the ground measurements. In general, however, comparison of spring and fall results with ground data suggest that MLCD algorithm is sensitive to seasonal transitions in EVI values and successfully captures phenological patterns at Harvard Forest (Table 3, Fig. 10).

\subsubsection{Comparison with Hubbard Brook field data}

The Hubbard Brook Experimental Forest is located within the White Mountain National Forest in central New Hampshire with elevations ranging from 222 to $1015 \mathrm{~m}$ above sea level. Researchers at Hubbard Brook have been monitoring the phenology of selected sugar maple, American beech and yellow birch trees at specific sites located in five watersheds since 1989 (Bailey, 2001). The phenological stage

Table 3

Comparisons among phenological transition dates retrieved from MLCD C4 and C5 data and in situ data collected at Harvard forest for the time period 2001-2006. For MODIS transition dates, the table presents the mean and standard deviation in DOY for the pixels included in the analysis. $G_{\mathrm{O}}=$ onset date of EVI increase, $G_{\mathrm{M}}=$ onset date of EVI maximum, $G_{S}=$ onset date of EVI decrease, and $G_{D}=$ onset date of EVI minimum; BBD = Date of first budburst in the field data; PC = percent canopy budburst on date of $G_{0}$; FL1 = Percent of canopy where leaves have reached $75 \%$ of final size; FL2 = Percent of canopy where leaves have reached $95 \%$ of final size; $C L=$ percent of canopy with leaf coloring at time of $\mathrm{G}_{5}$; $\mathrm{FL}=$ percent of canopy where leaves have fallen at time of $\mathrm{G}_{\mathrm{S}} ; \mathrm{AGD}=$ average date of last green leaf in canopy; $\mathrm{G}_{\mathrm{L}}=$ percent of green leaves in the canopy at time of $\mathrm{G}_{\mathrm{D}}$; $\mathrm{TL}=$ percent of leaves remaining on the trees at time of mean $G_{D}$.

\begin{tabular}{|c|c|c|c|c|c|c|c|c|c|c|c|c|c|c|}
\hline \multirow[t]{3}{*}{ Year } & \multicolumn{4}{|l|}{$G_{\mathrm{O}}$} & \multicolumn{3}{|l|}{$G_{\mathrm{M}}$} & \multicolumn{3}{|l|}{$G_{S}$} & \multicolumn{4}{|l|}{$G_{\mathrm{D}}$} \\
\hline & \multirow{2}{*}{$\begin{array}{l}\text { MODIS } \\
\overline{\mathrm{x}} \pm \sigma\end{array}$} & \multicolumn{3}{|l|}{ BBD } & \multirow{2}{*}{$\begin{array}{l}\text { MODIS } \\
\overline{\mathrm{x}} \pm \sigma\end{array}$} & \multirow{2}{*}{$\begin{array}{l}\text { FL1 } \\
\overline{\mathrm{x}} \pm \sigma\end{array}$} & \multirow{2}{*}{$\begin{array}{l}\mathrm{FL} 2 \\
\overline{\mathrm{x}} \pm \sigma\end{array}$} & \multirow{2}{*}{$\begin{array}{l}\text { MODIS } \\
\overline{\mathrm{x}} \pm \sigma\end{array}$} & \multirow[t]{2}{*}{$\mathrm{CL}$} & \multirow[t]{2}{*}{$\mathrm{FL}$} & \multirow{2}{*}{$\frac{\text { MODIS }}{\overline{\mathrm{x}} \pm \sigma}$} & \multirow{2}{*}{$\begin{array}{l}\text { AGD } \\
\overline{\mathrm{x}} \pm \sigma\end{array}$} & \multirow[t]{2}{*}{ GL } & \multirow[t]{2}{*}{$\mathrm{TL}$} \\
\hline & & $\overline{\mathrm{x}} \pm \sigma$ & Range & PC & & & & & & & & & & \\
\hline 2001 & $\begin{array}{l}108 \pm 5(C 5) \\
119 \pm 2(C 4)\end{array}$ & $125 \pm 9$ & $109-156$ & 8.25 & $\begin{array}{l}157 \pm 7(\mathrm{C} 5) \\
158 \pm 3(\mathrm{C} 4)\end{array}$ & $87 \pm 16$ & $72 \pm 23$ & $\begin{array}{l}237 \pm 6(\mathrm{C} 5) \\
238 \pm 4(\mathrm{C} 4)\end{array}$ & 1 & 0.16 & $\begin{array}{l}310 \pm 3(\mathrm{C} 5) \\
319 \pm 2(\mathrm{C} 4)\end{array}$ & $291 \pm 10$ & 0.91 & 5.5 \\
\hline 2002 & $\begin{array}{l}102 \pm 16(\mathrm{C} 5) \\
123 \pm 1(\mathrm{C} 4)\end{array}$ & $117 \pm 12$ & $106-153$ & 15.4 & $\begin{array}{l}173 \pm 7(\mathrm{C} 5) \\
167 \pm 2(\mathrm{C} 4)\end{array}$ & $98 \pm 2$ & $94 \pm 4$ & $\begin{array}{l}241 \pm 11(C 5) \\
233 \pm 3(C 4)\end{array}$ & 0.3 & 0.10 & $\begin{array}{l}315 \pm 5(C 5) \\
316 \pm 2(C 4)\end{array}$ & $296 \pm 6$ & 0.00 & 9 \\
\hline 2003 & $\begin{array}{l}125 \pm 4(\mathrm{C} 5) \\
129 \pm 2(\mathrm{C} 4)\end{array}$ & $126 \pm 9$ & $105-140$ & 33.0 & $\begin{array}{l}169 \pm 6(\mathrm{C} 5) \\
163 \pm 2(\mathrm{C} 4)\end{array}$ & 100 & $90 \pm 6$ & $\begin{array}{l}233 \pm 14(\mathrm{C} 5) \\
234 \pm 6(\mathrm{C} 4)\end{array}$ & 1.5 & 0.16 & $\begin{array}{l}307 \pm 5(C 5) \\
313 \pm 2(C 4)\end{array}$ & $290 \pm 5$ & 0.02 & 10 \\
\hline 2004 & $\begin{array}{l}111 \pm 4(\mathrm{C} 5) \\
119 \pm 2(\mathrm{C} 4)\end{array}$ & $123 \pm 6$ & $110-140$ & 5.0 & $\begin{array}{l}157 \pm 11(\mathrm{C} 5) \\
157 \pm 3(\mathrm{C} 4)\end{array}$ & 100 & $87 \pm 7$ & $\begin{array}{l}235 \pm 11(\mathrm{C} 5) \\
236 \pm 4(\mathrm{C} 4)\end{array}$ & 1.1 & 0.10 & $\begin{array}{l}308 \pm 6(\mathrm{C} 5) \\
312 \pm 3(\mathrm{C} 4)\end{array}$ & $293 \pm 6$ & 0.18 & 8 \\
\hline 2005 & $114 \pm 11(\mathrm{C} 5)$ & $125 \pm 10$ & $109-141$ & 16.5 & $167 \pm 8(C 5)$ & $97 \pm 4$ & $88 \pm 8$ & $224 \pm 12(C 5)$ & 0.9 & 0.16 & $315 \pm 6(C 5)$ & $296 \pm 6$ & 0.00 & 3 \\
\hline 2006 & $115 \pm 3(\mathrm{C} 5)$ & $123 \pm 7$ & $107-137$ & 15.0 & $167 \pm 5(\mathrm{C} 5)$ & $99 \pm 1$ & $97 \pm 2$ & $230 \pm 4(C 5)$ & 1.8 & 0.80 & $303 \pm 5(\mathrm{C} 5)$ & $287 \pm 9$ & 0.69 & 10 \\
\hline
\end{tabular}


of each tree is measured, through weekly visits in spring and autumn, on a canopy development index (CDI) that ranges from 0 to 4 . Every plot record consists of observations on three trees each for sugar maple, yellow birch, and American beech. Values for the CDI depend on the season (spring or fall), and provide a measure of leaf emergence and canopy development in the spring, and leaf coloration and leaf drop in the fall. Specific details are available at http://www. hubbardbrook.org/data/dataset.php?id=51\#.

MLCD transition dates at Hubbard Brook and their associated standard deviations are listed in Table 4 along with canopy conditions quantified using the mean CDI at or close to MLCD transition dates. As for Harvard Forest, results from C4 are included for comparison. As we described above, ground measurement plots at Hubbard Brook span five watersheds. To allow comparisons with MLCD results, sixty-six $500-\mathrm{m}$ MODIS pixels covering the geographic extent of these watersheds were averaged for this analysis. Also, because measurements at Hubbard Brook are collected weekly, it is difficult to compare these insitu data with MODIS day of year transition dates. Hence, measured CDI values correspond to a fixed number of days $(\Delta)$ before or after the MODIS transition date. A $\Delta$ value of zero means that the reported canopy conditions coincide with the corresponding MODIS transition date. Negative values of $\Delta$ refer to the number of days that the in-situ measurements were collected before the MLCD transition date, and vice-versa.

MLCD data are generally in good agreement with the ground measurements at Hubbard Brook. With the exception of $G_{O}$ in 2006, MLCD retrievals for $G_{\mathrm{O}}, G_{\mathrm{M}}$ and $G_{\mathrm{D}}$ broadly correspond to reasonable values of the CDI. However, values for $G_{S}$ indicate that canopy senescence begins in mid to late August, nearly 11 to 39 days before the CDI begins to decrease. Part of this discrepancy arises from the fact that in 2001-2006 fall CDI data were not collected until early September. Further, documentation for the CDI indicates that a value of 4.0 in the fall allows for modest levels of leaf coloring. More generally, however, senescence tends to be quite gradual, and estimating a specific date associated with the onset of EVI decrease is difficult to detect from remote sensing. Thus, the results for $G_{s}$ probably reflect a combination of factors related to both data collection on the ground and lower overall quality in $G_{\mathrm{S}}$ from MODIS relative to $G_{\mathrm{O}}, G_{\mathrm{M}}$ and $G_{\mathrm{D}}$. Results for $G_{\mathrm{S}}$ may also reflect the sensitivity of the EVI to seasonal variation in leaf properties such as water content (Cheng et al., 2006).

As we noted above, MODIS Go values at Hubbard Brook in 2006 are unusually late with a mean value of 151 , suggesting a problem with the algorithm or input data. Inspection of input data during this period reveals two related issues. First, NBAR snow flags indicate the presence of snow at Hubbard Brook for the eight-day period starting on DOY 129. Second, NBAR blue band (MODIS band 3) data are missing during the same period, leading to missing EVI data during this period. The EVI time series for Hubbard Brook is shown in Fig. 11, where the

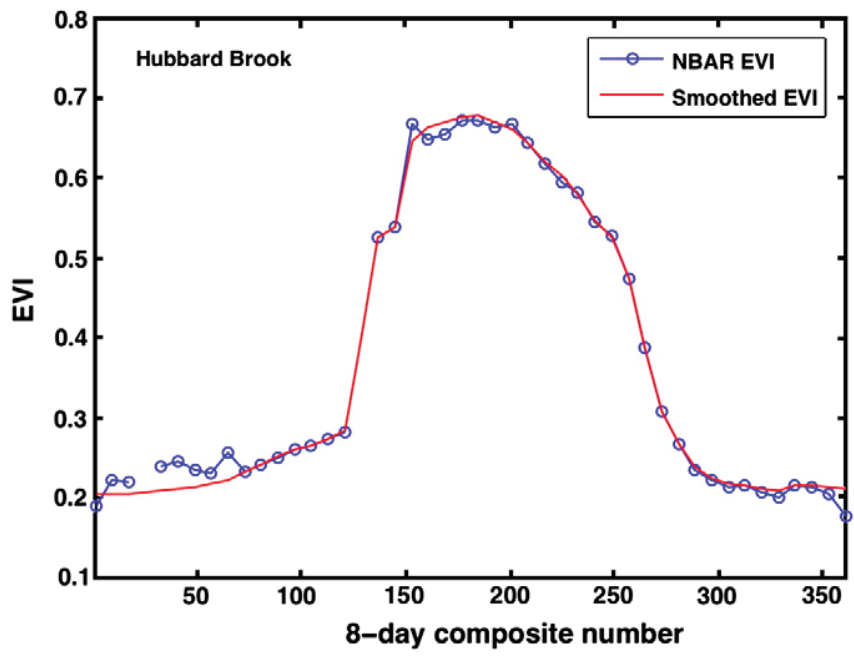

Fig. 11. Time series showing NBAR-EVI data at Hubbard Brook before and after smoothing used to pre-process data prior to estimating transition dates. The data gap, filled by linear interpolation around DOY 129 , is clearly evident.

data gap is clearly evident. Thus, the combination of missing data and snow-flags in the input data causes the algorithm to spuriously estimate the onset of EVI increase well after DOY 129. Indeed, when the snow-flags from 2006 are replaced with values from 2005, the mean value for $G_{O}$ becomes DOY 121 . This appears to be a relatively unusual situation, but requires correction in the next version of the product.

\section{Discussion and conclusions}

The goal of this paper was to present an overview and characterization of the Collection 5 MODIS land cover dynamics product through a series of inter-comparison exercises with the C4 product and available data from two field sites. In addition, the C5 product was evaluated to assess the nature and magnitude of variability captured by the product at interannual time scales. Results from a comparison of C4 and C5 data for six tiles spanning a range of climate and land cover types show that the $\mathrm{C} 4$ and $\mathrm{C} 5$ products are similar, with some notable differences. Most importantly, the C5 product has higher spatial resolution (500-m versus $1-\mathrm{km}$ in $\mathrm{C4}$ ) and fewer missing values outside of the tropics. C5 transition dates are generally consistent with C4, except in the tropics, where phenological dynamics are often more subtle and the frequency of missing data caused by clouds and aerosols is higher. At interannual time scales, observed year-to-year variability in C5 data is consistent with expected ranges associated with interannual climate variability. Larger differences at

Table 4

Mean and standard deviation in phenological transition dates (DOY) retrieved from C4 and C5 MODIS data at Hubbard Brook Experimental Forest for 2001-2006. $\Delta$ is the number of days before or after the MLCD value that in-situ data were collected, CDI is the canopy development index. Values in parentheses provide the range in CDI values on the day of year corresponding to the MLCD estimated transition date.

\begin{tabular}{|c|c|c|c|c|c|c|c|c|c|c|c|c|}
\hline \multirow[t]{3}{*}{ Year } & \multicolumn{3}{|l|}{$G_{\mathrm{O}}$} & \multicolumn{3}{|l|}{$G_{M}$} & \multicolumn{3}{|l|}{$G_{\mathrm{S}}$} & \multicolumn{3}{|l|}{$G_{\mathrm{D}}$} \\
\hline & MODIS & $\Delta$ & CDI & MODIS & $\Delta$ & CDI & MODIS & $\Delta$ & CDI & MODIS & $\Delta$ & CDI \\
\hline & \multicolumn{3}{|l|}{$\overline{\overline{\mathrm{x}} \pm \sigma}$} & \multicolumn{3}{|l|}{$\overline{\bar{x} \pm \sigma}$} & \multicolumn{3}{|l|}{$\overline{\bar{x} \pm \sigma}$} & \multicolumn{3}{|l|}{$\overline{\bar{x} \pm \sigma}$} \\
\hline \multirow[t]{2}{*}{2001} & $118 \pm 6(\mathrm{C} 5)$ & 10 & $1.8(1.4,2.2)$ & $162 \pm 8(\mathrm{C} 5)$ & 0 & $4(4,4)$ & $242 \pm 9(\mathrm{C} 5)$ & 11 & $3.5(3.2,3.7)$ & $299 \pm 8(C 5)$ & -4 & $0.3(0,0.5)$ \\
\hline & $133 \pm 6(C 4)$ & & & $159 \pm 2(C 4)$ & & & $261 \pm 7(C 4)$ & & & $306 \pm 2(C 4)$ & & \\
\hline \multirow[t]{2}{*}{2002} & $122 \pm 10(\mathrm{C} 5)$ & 4 & $0.7(0.3,1)$ & $169 \pm 7(\mathrm{C} 5)$ & -8 & $4(4,4)$ & $222 \pm 11(\mathrm{C} 5)$ & 24 & $4(3.8,4)$ & $293 \pm 9(\mathrm{C} 5)$ & 1 & $1.4(1,1.8)$ \\
\hline & $138 \pm 5(\mathrm{C} 4)$ & & & $168 \pm 5(C 4)$ & & & $246 \pm 4(C 4)$ & & & $310 \pm 3(C 4)$ & & \\
\hline \multirow[t]{2}{*}{2003} & $133 \pm 8(C 5)$ & NA & NA & $168 \pm 7(\mathrm{C} 5)$ & -1 & $3.9(3.8,4)$ & $226 \pm 9(\mathrm{C} 5)$ & 32 & $3.8(3.6,3.9)$ & $300 \pm 4(C 5)$ & 1 & $0.3(0.1,0.4)$ \\
\hline & $137 \pm 2(\mathrm{C} 4)$ & & & $168 \pm 3(\mathrm{C} 4)$ & & & $241 \pm 4(\mathrm{C} 4)$ & & & $303 \pm 2(C 4)$ & & \\
\hline \multirow[t]{2}{*}{2004} & $116 \pm 6(\mathrm{C} 5)$ & 9 & $1.1(1,1.4)$ & $164 \pm 9(\mathrm{C} 5)$ & -11 & $4(4,4)$ & $226 \pm 15(\mathrm{C} 5)$ & 38 & $3.7(3.5,3.9)$ & $299 \pm 6(C 5)$ & 0 & $0.6(0.3,0.9)$ \\
\hline & $127 \pm 4(\mathrm{C} 4)$ & & & $164 \pm 3(C 4)$ & & & $231 \pm 8(C 4)$ & & & $304 \pm 3(C 4)$ & & \\
\hline 2005 & $122 \pm 11(\mathrm{C} 5)$ & 0 & $0.2(0.1,0.3)$ & $162 \pm 7(\mathrm{C} 5)$ & -5 & $3.8(3.7,3.9)$ & $233 \pm 9$ (C5) & 29 & $4(4,4)$ & $301 \pm 13(\mathrm{C} 5)$ & -4 & $1.3(0.9,1.7)$ \\
\hline 2006 & $151 \pm 6(\mathrm{C} 5)$ & -1 & $3.6(3.3,3.8)$ & $173 \pm 13(\mathrm{C} 5)$ & -10 & $4(4,4)$ & $229 \pm 13(\mathrm{C} 5)$ & 25 & $3.8(3.7,3.9)$ & $289 \pm 5(\mathrm{C} 5)$ & 0 & $0.5(0.3,0.7)$ \\
\hline
\end{tabular}


local and regional scales may also reflect changing surface conditions in response to climate forcing, disturbance (fires and insect infestations), and human management. Finally, MLCD transition dates from C5 were compared with field-measurements of forest canopy phenology at Harvard Forest and Hubbard Brook for 2001-2006. The results show that retrieved transition dates are generally realistic relative to field observations at each of these sites, but that MODISbased estimates of phenological transition dates at the end of the growing season have larger uncertainty (and perhaps bias) relative to start-of-season metrics.

Methods and data for assessment and validation of phenology metrics obtained from remote sensing is a critical issue requiring attention within the land surface phenology community. For this work, we relied on field data from two field sites in the northeastern United States. While these data provide measurements from a large number of trees and cover the period that MODIS has been collecting data, the limited geographic extent and ecological conditions in which these data were collected are clearly not sufficient to provide robust characterization of error in the MLCD product. Unfortunately, relatively few data sets are available that have been collected based on an explicit design in support of remote sensing product validation; this dearth of data is clearly limiting progress in this area (Liang \& Schwartz, 2009). In particular, data sets collected across a wider range of ecosystems and that specifically measure phenology on the ground at spatial scales commensurate with moderate resolution remote sensing are urgently required. Intercomparison efforts such as those performed by White et al. (2009) provide useful guidance regarding differences and similarities among algorithm results. However, until data sets are available that have been collected using sample designs specifically implemented in support of remote sensing validation activities, it will be difficult to make meaningful conclusions regarding the strengths, weaknesses, and comparative accuracies of different algorithms and remote sensing products. Ongoing activities such as those coordinated by the National Phenology Network and other efforts using webcams (Richardson et al., 2009a,b) offer substantial promise for addressing this data gap, but current data is clearly not sufficient for global validation of land surface phenology products.

The MODIS Land Cover Dynamics Product is one of a number of remote sensing-based products being used to generate regional to global scale maps of vegetation phenology. While the results presented in this and other work show that remote sensing can provide good quality results over large regions (e.g., temperate deciduous vegetation and agriculture), a number of important questions need to be resolved in order to both address weaknesses identified in this paper and to better meet the needs of scientists who wish to use these products. In addition to providing better characterization of the error and uncertainty associated with MLCD results, ongoing efforts are focused on developing improved methods for pre-processing input data (including screening for snow), and improved understanding of the nature and utility of retrieved phenological values in environments that present challenges for remote sensing including high latitude, arid, and tropical ecosystems.

\section{Acknowledgements}

The research presented in this paper was supported by NASA Cooperative Agreement number NNX08AE61A and by a sub-contract from the University of Arizona under NASA grant number NNX08AE61A. The authors gratefully acknowledge data supplied by the Harvard Forest and Hubbard Brook LTER sites.

\section{References}

Ahl, D. E., Gower, S. T., Burrows, S. N., Shabanov, N. V., Myneni, R. B., \& Knyazikhin, Y. (2006). Monitoring spring canopy phenology of a deciduous broadleaf forest using MODIS. Remote Sensing of Environment, 104, 88-95.
Angert, A., Biraud, S., Bonfils, C., Henning, C. C., Buermann, W., Pinzon, J., et al. (2005). Drier summers cancel out the $\mathrm{CO} 2$ uptake enhancement induced by warmer springs. Proceedings of the National Academy of Sciences of the United States of America, 102, 10823-10827.

Baccini, A., Friedl, M. A., Woodcock, C. E., \& Zhu, Z. (2008). Scaling field data to calibrate and validate moderate spatial resolution remote sensing models. Photogrammetric Engineering and Remote Sensing, 73(8), 945-954.

Bailey, A. (2001). Routine phenology measurements: USDA Forest Service, Hubbard Brook Experimental Forest West Thornton, NH (http://www.hubbardbrook.org/ data/dataset.php?id=51\#)

Baldocchi, D., Falgle, E., \& Wilson, K. (2001). A spectral analysis of biosphereatmosphere trace fas flux densities and micrometeorological variables across hour to multi-year time scales. Agricultural and Forest Meteorology, 107(1), 1-276.

Buermann, W., Wang, Y. J., Dong, J. R., Zhou, L. M., Zeng, X. B., Dickinson, R. E., et al. (2002). Analysis of a multiyear global vegetation leaf area index data set. Journal of Geophysical Research-Atmospheres, 107, 1-16.

Bunn, A. G., \& Goetz, S. J. (2006). Trends in satellite-observed circumpolar photosynthetic activity from 1982 to 2003: The influence of seasonality, cover type, and vegetation density. Earth Interactions, 10, 1-19.

Chen, F., \& Dudhia, J. (2001). Coupling an advanced land surface-hydrology model with the Penn State-NCAR MM5 modeling system. Part I: Model implementation and sensitivity. Monthly Weather Review, 129, 569-585.

Cheng, Y., Gamon, J. A., Fuentes, D. A., Mao, Z., Sims, D. A., Qui, H. L., et al. (2006). A multi-scale analysis of dynamic optical signals in a Southern California chaparral ecosystem: A comparison of field, AVIRIS and MODIS data. Remote Sensing of Environment, 103, 369-378.

Churkina, G., Schimel, D., Braswell, B. H., \& Xiao, X. (2005). Spatial analysis of growing season length control over net ecosystem exchange. Global Change Biology, 11, 1777-1787.

Cleland, E. E., Chuine, I., Menzel, A., Mooney, H. A., \& Schwartz, M. D. (2007). Shifting plant phenology in response to global change. Trends in Ecology \& Evolution, 22, 357-365.

Cooke, J. E. K., \& Weih, M. (2005). Nitrogen storage and seasonal nitrogen cycling in Populus: Bridging molecular physiology and ecophysiology. New Phytologist, 167, 19-30.

De Beurs, K. M., \& Henebry, G. M. (2005). Land surface phenology and temperature variation in the International Geosphere-Biosphere Program high latitude transects. Global Change Biology, 11(5), 779-790.

Delbart, N., Le Toan, T., Kergoat, L., \& Fedotova, V. (2006). Remote sensing of spring phenology in boreal regions: A free of snow-effect method using NOAA-AVHRR and SPOT-VGT data (1982-2004). Remote Sensing of Environment, 101, 52-62.

Dye, D. G., \& Tucker, C. J. (2003). Seasonality and trends of snow-cover, vegetation index, and temperature in northern Eurasia. Geophysical Research Letters, 30, 58.

Fisher, J. I., \& Mustard, J. F. (2007). Cross-scalar satellite phenology from ground, Landsat, and MODIS data. Remote Sensing of Environment, 109, 261-273.

Friedl, M. A., Sulla-Menashe, D., Tan, B., Schneider, A., Ramankutty, N., Sibley, A., et al (2010). MODIS collection 5 global land cover: Algorithm refinements and characterization of new datasets. Remote Sensing of Environment, 114(1), 168-182.

Ganguly, S., Samanta, A., Schull, M. A., Shabanov, N. V., Milesi, C., Nemani, R. R., et al (2008). Generating vegetation leaf area index Earth system data record from multiple sensors. Part 2: Implementation, analysis and validation. Remote Sensing of Environment, 112, 4318-4332.

Goetz, S. J., Bunn, A. G., Fiske, G. J., \& Houghton, R. A. (2005). Satellite-observed photosynthetic trends across boreal North America associated with climate and fire disturbance. Proceedings of the National Academy of Sciences of the United States of America, 102, 13521-13525.

Goward, S. N., Tucker, C. J., \& Dye, D. G. (1985). North-American vegetation patterns observed with the NOAA-7 Advanced Very High-Resolution Radiometer. Vegetation, 64, 3-14.

Heimann, M., Esser, G., Haxeltine, A., Kaduk, J., Kicklighter, D. W., Knorr, W., et al. (1998). Evaluation of terrestrial Carbon Cycle models through simulations of the seasonal cycle of atmospheric $\mathrm{CO}_{2}$ : First results of a model intercomparison study. Global Biogeochemical Cycles, 12(1), 1-24.

Herold, M., Mayaux, P., Woodcock, C. E., Baccini, A., \& Schmullius, C. (2008). Some challenges in global land cover mapping: An assessment of agreement and accuracy in existing $1 \mathrm{~km}$ datasets. Remote Sensing of Environment, 112, 2538-2556.

Hogg, E. H., Price, D. T., \& Black, T. A. (2000). Postulated feedbacks of deciduous forest phenology on seasonal climate patterns in the western Canadian interior. Journal of Climate, 13, 4229-4243.

Huang, D., Yang, W. Z., Tan, B., Rautiainen, M., Zhang, P., Hu, J. N., et al. (2006). The importance of measurement errors for deriving accurate reference leaf area index maps for validation of moderate-resolution satellite LAI products. IEEE Transaction on Geoscience and Remote Sensing, 44, 1866-1871.

Huete, A., Didan, K., Miura, T., Rodriguez, E. P., Gao, X., \& Ferreira, L. G. (2002). Overview of the radiometric and biophysical performance of the MODIS vegetation indices. Remote Sensing of Environment, 83, 195-213.

Huete, A. R., Didan, K., Shimabukuro, Y. E., Ratana, P., Saleska, S. R., Hutyra, L. R., et al. (2006). Amazon rainforests green-up with sunlight in dry season. Geophysical Research Letters, 33, L06405. doi:10.1029/2005GL025583

Jakubauskas, M. E., Legates, D. R., \& Kastens, J. H. (2001). Harmonic analysis of time-series AVHRR NDVI data. Photogrammetric Engineering and Remote Sensing, 67, 461-470.

Jonsson, P., \& Eklundh, L. (2002). Seasonality extraction by function fitting to time-series of satellite sensor data. IEEE Transactions on Geoscience and Remote Sensing, 40, 1824-1832.

Justice, C. O., Townshend, J. R. G., Holben, B. N., \& Tucker, C. J. (1985). Analysis of the phenology of global vegetation using meteorological satellite data. International Journal of Remote Sensing, 6, 1271-1318.

Liang, L., \& Schwartz, M. (2009). Landscape phenology: An integrative approach to seasonal vegetation dynamics. Landscape Ecology, 24(4), 465-472. 
Lotsch, A., Friedl, M. A., Anderson, B. T., \& Tucker, C. J. (2005). Response of terrestrial ecosystems to recent Northern Hemispheric drought. Geophysical Research Letters, 32, L06705. doi:10.1029/2004GL022043

Medvigy, D., Wofsy, S. C., Munger, J. W., Hollinger, D. Y., \& Moorcroft, P. R. (2009). Mechanistic scaling of ecosystem function and dynamics in space and time: Ecosystem Demography model version 2. Journal of Geophysical Research, 114, G01002. doi:10.1029/2008JG000812

Moody, A., \& Johnson, D. M. (2001). Land-surface phenologies using the discrete Fourier transform. Remote Sensing of Environment, 75(3), 305-323.

Moore, K. E., Fitzjarrald, D. R., Sakai, R. K., Goulden, M. L., Munger, J. W., \& Wofsy, S. C. (1996). Seasonal variation in radiative and turbulent exchange at a deciduous forest in Central Massachusetts. Journal of Applied Meteorology, 35, 122-134.

Morisette, J. T., Privette, J. L., \& Justice, C. O. (2002). A framework for the validation of MODIS land products. Remote Sensing of Environment, 83(1-2), 77-96.

Morisette, J. T., Richardson, A. D., Knapp, A. K., Fisher, J. I., Graham, E. A., Abatzoglou, J., et al. (2009). Tracking the rhythm of the seasons in the face of global change: Phenological research in the 21st century. Frontiers in Ecology and the Environment, 7, 253-260.

Moulin, S., Kergoat, L., Viovy, N., \& Dedieu, G. (1997). Global-scale assessment of vegetation phenology using NOAA/AVHRR satellite measurements. Journal of Climate, 10, 1154-1170.

Myneni, R. B., Keeling, C. D., Tucker, C. J., Asrar, G., \& Nemani, R. R. (1997). Increased plant growth in the northern high latitudes from 1981 to 1991. Nature, 386, 698-702.

Myneni, R. B., Yang, W., Nemani, R. R., Huete, A. R., Dickinson, R. E., Knyazikhin, Y., et al. (2007). Large seasonal swings in leaf area of Amazon rainforests. Proceedings of the National Academy of Sciences of the United States of America, 104(12), 4820-4823.

Ollinger, S. V., Richardson, A. D., Martin, M. E., Hollinger, D. Y., Frolking, S. E., Reich, P. B. et al. (2008). Canopy nitrogen, carbon assimilation, and albedo in temperate and boreal forests: Functional relations and potential climate feedbacks. Proceedings of the National Academy of Sciences of the United States of America, 105(49), 19335-19340.

Reed, B. C., Brown, J. F., VanderZee, D., Loveland, T. R., Merchant, J. W., \& Ohlen, D. O. (1994). Measuring phenological variability from satellite imagery. Journal of Vegetation Science, 5, 703-714.

Richardson. A. D., Black, T. A., Ciais, P., Yuste, J. C., Delbart, N., Dunn, A. L., Friedl, M. A., Gobron, N., Hollinger, D. Y., Kutsch, W. L., Longdoz, B., Luyssaert, S., Migliavacca, M. Misson, L., Montagnani, L., Munger, J. W., Moors, E., Piao, S., Rebmann, C., Reichstein, M., Saigusa, N., Stöckli, R., Stoy, P. C., Tomelleri, E., Vargas, R., Varlagin, A., \& Vesala, $\mathrm{T}$. (in press). Influence of spring and autumn phenological switches on forest ecosystem productivity. Philosophical Transactions of the Royal Society.

Richardson, A. D., Braswell, B. H., Hollinger, D., Jenkins, J. P., \& Ollinger, S. V. (2009a). Near-surface remote sensing of spatial and temporal variation in canopy phenology. Ecological Applications, 19(6), 1417-1428.

Richardson, A. D., Hollinger, D. Y., Dail, D. B., Lee, J. T., Munger, J. W., \& O'Keefe, J. (2009b). Influence of spring phenology on seasonal and annual carbon balance in two contrasting New England forests. Tree Physiology, 29, 321-331.

Richardson, A. D., \& O'Keefe, J. (2009). Phenological differences between understory and overstory: A case study using the long term Harvard Forest records. In A. Noormets (Ed.), Phenology of Ecosystem Processes (pp. 87-117). New York: Springer.

Schaaf, C. B., Gao, F., Strahler, A. H., Lucht, W., Li, X. W., Tsang, T., et al. (2002). First operational BRDF, albedo nadir reflectance products from MODIS. Remote Sensing of Environment, 83, 135-148.
Schwartz, M. D., \& Hanes, J. M. (2009). Intercomparing multiple measures of the onset of spring in eastern North America. International Journal of Climatology. doi:10.1002/ joc. 2008

Soja, A. J., Tchebakova, N. M., French, N. H. F., Flannigan, M. D., Shugart, H. H., Stocks, B. J., et al. (2007). Climate-induced boreal forest change: Predictions versus current observations. Global and Planetary Change, 56, 274-296.

Tan, B., Hu, J. N., Huang, D., Yang, W. Z., Zhang, P., Shabanov, N. V., et al. (2005a). Assessment of the broadleaf crops leaf area index product from the Terra MODIS instrument. Agricultural and Forest Meteorology, 135, 124-134.

Tan, B., Hu, J. N., Zhang, P., Huang, D., Shabanov, N., Weiss, M., et al. (2005b). Validation of Moderate Resolution Imaging Spectroradiometer leaf area index product in croplands of Alpilles, France. Journal of Geophysical Research-Atmospheres, 110.

Tan, B., Woodcock, C. E., Hu, J., Zhang, P., Ozdogan, M., Huang, D., et al. (2006). The impact of gridding artifacts on the local spatial properties of MODIS data: Implications for validation, compositing, and band-to-band registration across resolutions. Remote Sensing of Environment, 105, 98-114.

Thompson, D. R., \& Wehmanen, O. A. (1979). Using Landsat digital data to detect moisture stress. Photogrammetric Engineering and Remote Sensing, 45, 201-207.

Wan, Z. M., Zhang, Y. L., Zhang, Q. C., \& Li, Z. L. (2002). Validation of the land-surface temperature products retrieved from Terra Moderate Resolution Imaging Spectroradiometer data. Remote Sensing of Environment, 83, 163-180.

Weiss, M., Baret, F., Garrigues, S., \& Lacaze, R. (2007). LAI and fAPAR CYCLOPES global products derived from VEGETATION. Part 2: Validation and comparison with MODIS collection 4 products. Remote Sensing of Environment, 110, 317-331.

White, M. A., de Beurs, K. M., Didan, K., Inouye, D. W., Richardson, A., Jensen, O. P., et al. (2009). Intercomparison, interpretation, and assessment of spring phenology in North America estimated from remote sensing for 1982-2006. Global Change Biology, 15(10), 2335-2359.

White, M. A., Thornton, P. E., \& Running, S. W. (1997). A continental phenology model for monitoring vegetation responses to interannual climatic variability. Global Biogeochemical Cycles, 11, 217-234.

Yang, R., Friedl, M. A., \& Ni, W. (2001). Parameterization of shortwave radiation fluxes for nonuniform vegetation canopies in land surface models. Journal of Geophysical Research, 106(D13), 14275-14286.

Zhang, X., Friedl, M. A., \& Schaaf, C. B. (2006). Global vegetation phenology from Moderate Resolution Imaging Spectroradiometer (MODIS): Evaluation of global patterns and comparison with in situ measurements. Journal of Geophysical Research, 111, G04017.

Zhang, X., Friedl, M. A., \& Schaaf, C. B. (2009). Sensitivity of vegetation phenology detection to the temporal resolution of satellite data. International Journal of Remote Sensing, 30(8), $2061-2074$.

Zhang, X., Friedl, M. A., Schaaf, C. B., Strahler, A. H., Hodges, J. C. F., Gao, F., et al. (2003). Monitoring vegetation phenology using MODIS. Remote Sensing of Environment, 84 $471-475$.

Zhang, X., Tarpley, D., \& Sullivan, J. T. (2007). Diverse responses of vegetation phenology to a warming climate. Geophysical Research Letters, 34, L19405. doi:10.1029/2007GL031447

Zhou, L. M., Tucker, C. J., Kaufmann, R. K., Slayback, D., Shabanov, N. V., \& Myneni, R. B. (2001). Variations in northern vegetation activity inferred from satellite data of vegetation index during 1981 to 1999. Journal of Geophysical Research-Atmospheres, 106, 20069-20083. 